\title{
DESENVOLVIMENTO E AVALIAÇÃO DE UM SISTEMA DE IRRIGAÇÃO AUTOMATIZADO PARA ÁREAS EXPERIMENTAIS
}

\section{Rodrigo Otávio Rodrigues de Melo Souza}

\author{
Dissertação apresentada à Escola \\ Superior de Agricultura "Luiz de \\ Queiroz", Universidade de São Paulo, \\ para obtenção do título de Mestre em \\ Agronomia, Área de concentração: \\ Irrigação e Drenagem.
}

\section{PIRACICABA}

Estado de São Paulo - Brasil

Novembro - 2001 


\title{
DESENVOLVIMENTO E AVALIAÇÃO DE UM SISTEMA DE IRRIGAÇÃO AUTOMATIZADO PARA ÁREAS EXPERIMENTAIS
}

\author{
Rodrigo Otávio Rodrigues de Melo Souza \\ Engenheiro Agrícola
}

Orientador: Prof. Dr. TARLEI ARRIEL BOTREL

Dissertação apresentada à Escola Superior de Agricultura "Luiz de Queiroz", Universidade de São Paulo, para obtenção do título de Mestre em Agronomia, Área de concentração: Irrigação e Drenagem.

\section{PIRACICABA}

Estado de São Paulo - Brasil

Novembro - 2001 
Dados Internacionais de Catalogação na Publicação (CIP) DIVISÃO DE BIBLIOTECA E DOCUMENTAÇÃO - ESALQ/USP

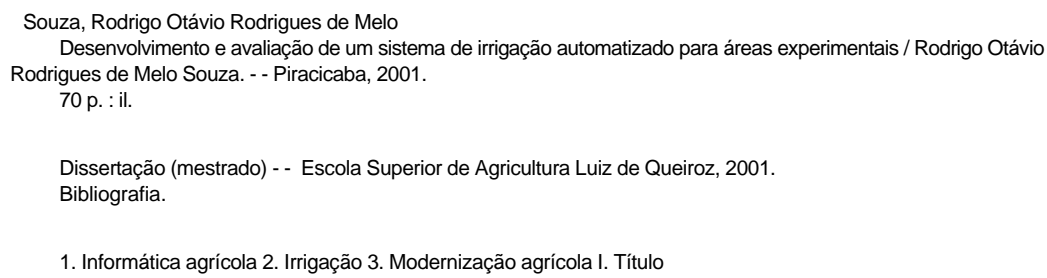

"Permitida a cópia total ou parcial deste documento, desde que citada a fonte - $\mathrm{O}$ autor" 


\section{DEDICO}

$\mathcal{A}$ meus queridos pais, $\mathcal{N}$ adyr e gonas

$\mathcal{A}$ meus irmãos, $\mathcal{N}$ ewton, Luís, Pedro, Matheus e Clarissa

À minha avó e madrinfra, Tita

"I amais considere seus estudos como uma obrigação, mas como uma oportunidade invejável (...) para aprender a confecer a influência libertadora da beleza do reino do Espírito, para seu próprio prazer pessoale para prove ito da comunidade à qual seu futuro trabalfo pertencer"

(Mensagem de Einste in a estudantes de Princenton, EUA) 


\section{AGRADECIMENTOS}

A Deus pela fé e esperança.

A meus pais pelos esforços, compreensão e apoio na formação moral e intelectual dos seus filhos.

À Escola Superior de Agricultura "Luiz de Queiroz" (ESALQ/USP), através do Departamento de Engenharia Rural, pelo apoio dispensado e acolhimento.

À Coordenadoria de Aperfeiçoamento de Pessoal de Nível Superior (CAPES), pela concessão de bolsa de estudos.

Ao prof. Dr. Tarlei Arriel Botrel, pelos ensinamentos oferecidos, pela orientação, amizade e incentivo.

Ao prof. Dr. Rubéns Duarte Coelho e Dr. Jarbas Honório de Miranda, pelas valiosas sugestões e colaborações.

Aos professores e colegas do Curso de Pós-Graduação em Irrigação e Drenagem, que formal ou informalmente contribuíram em minha formação científica e moral.

Ao Grupo de Estudos em Automação pelos ensinamentos, ajuda e amizade.

Aos funcionários do DER-ESALQ/USP, Davilmar, Sandra, César, Hélio, Antônio, Gilmar e Osvaldo, pelo apoio e atenção.

Aos colegas Rafael, Chryz, Valter e Luis Fernando pelo companheirismo e amizade.

À Joanne Moraes, pelo carinho, companhia, incentivo e apoio em todos os momentos. 


\section{SUMÁRIO}

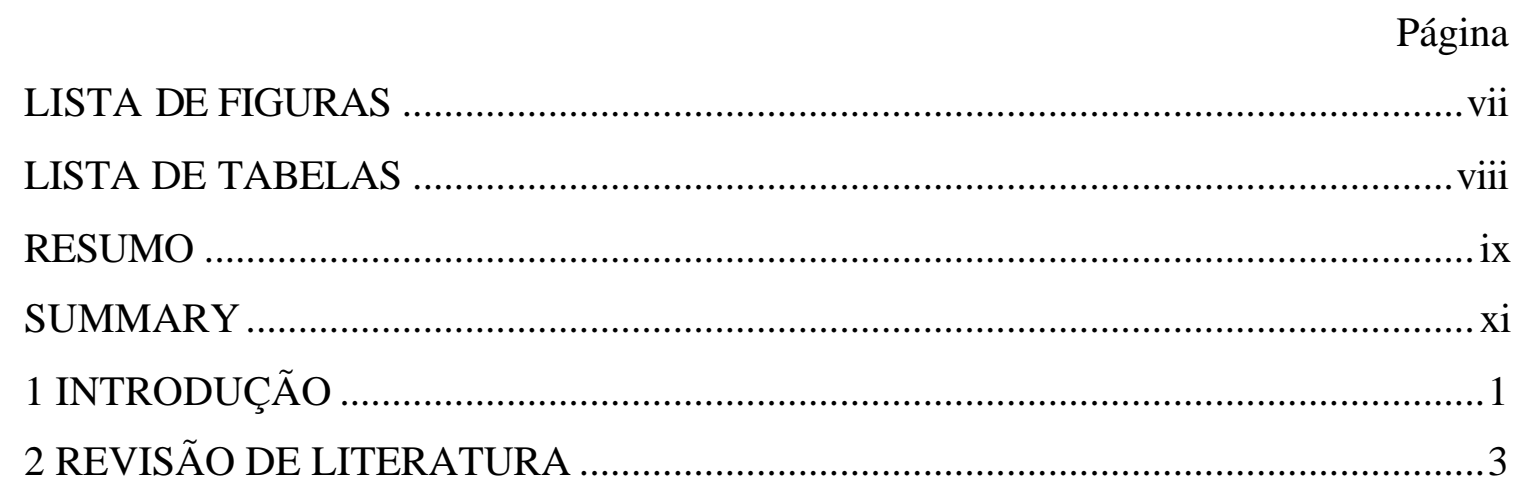

2.1 Eletrônica e automação ................................................................................ 3

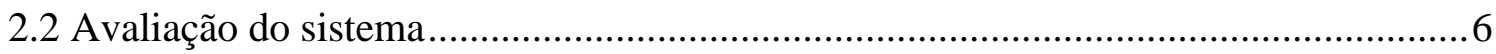

2.2.1 Uniformidade de distribuição de água ............................................................6

2.2.2 Coeficiente de variação de fabricação................................................................. 12

2.2.3 Relação vazão versus pressão ...................................................................... 14

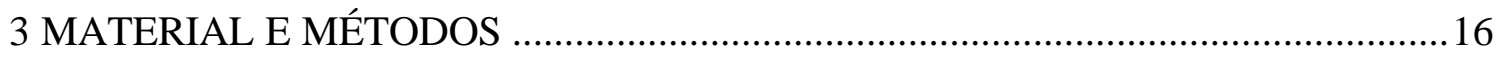

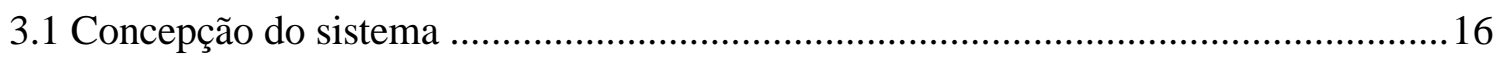

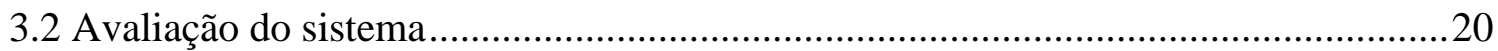

3.2.1 Uniformidade de distribuição de água .............................................................20

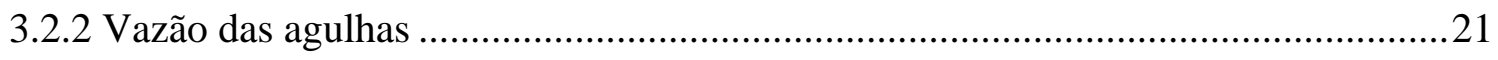

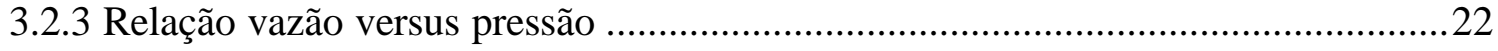

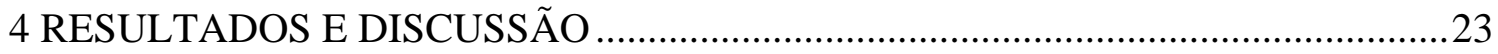

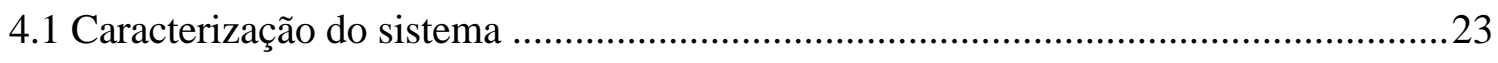

4.1.1 Comunicação com a porta paralela do computador ............................................23

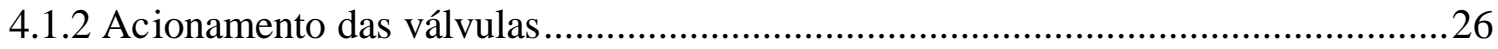

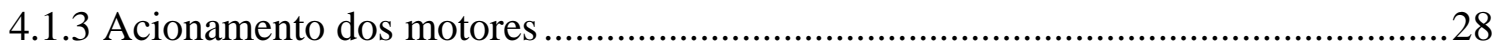




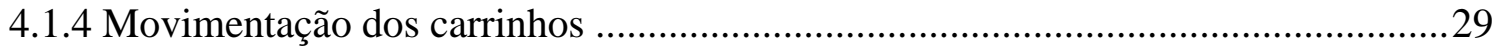

4.1.5 Programa para controle da irrigação ............................................................. 30

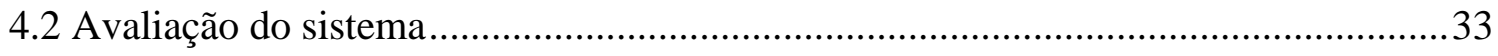

4.2.1 Uniformidade de distribuiç̧ão de água .................................................................33

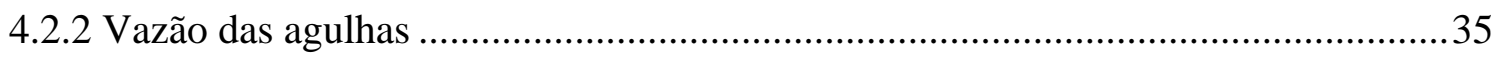

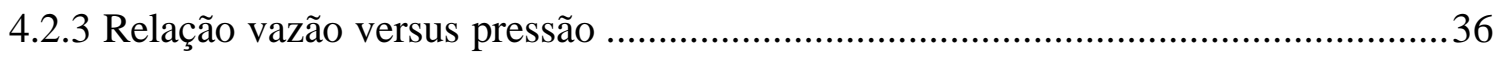

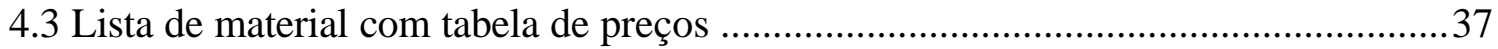

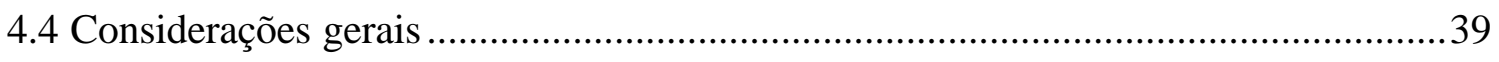

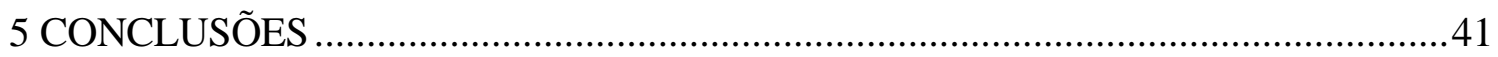

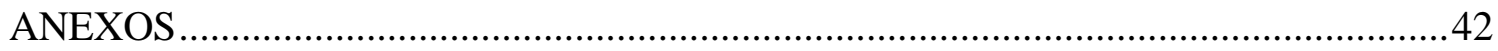

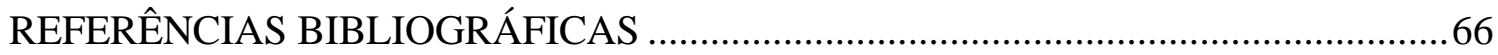




\section{LISTA DE FIGURAS}

Página

1 Esquema em perspectiva do sistema de irrigação ............................................... 18

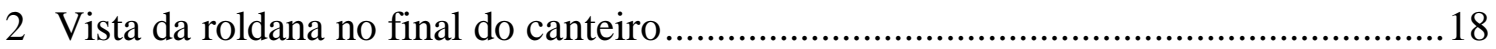

3 Vista superior do sistema de irrigação.............................................................. 19

4 Esquema de coleta dos dados de precipitação dos pluviômetros para o setor 1 ..........20

5 Esquema de cole ta dos dados de vazão ..................................................................22

6 Vista da comunicação entre computador e o meio externo via porta paralela ............23

7 Conector DB25 fêmea. Numeração dos pinos da porta paralela do PC ......................24

8 Válvula para injeção de água e válvula para injeção de fertilizante..........................26

9 Esquema do relé para acionamento das válvulas ................................................27

10 Esquema elétrico para acionamento do relé via porta paralela do computador ..........27

11 Motor responsável pela movimentação do sistema ...............................................28

12 Polarização direta do inversor de polaridade ........................................................29

13 Polarização invertida do inversor de polaridade .................................................29

14 Interruptor magnético instalado na extremidade do canteiro ....................................30

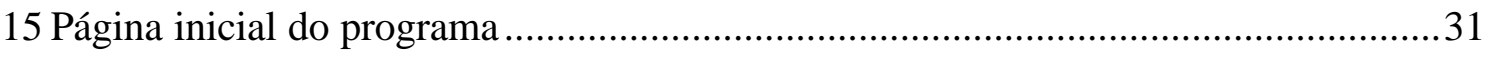

16 Entrada de dados para manejo da irrigação ............................................................ 32

17 Informações sobre as últimas irrigações .................................................................. 32

18 Fluxograma utilizado no desenvolvimento do programa .......................................33

19 Gráfico representativo da relação vazão versus pressão das agulhas ..........................37 


\section{LISTA DE TABELAS}

Página

1 Classificação da uniformidade de vazão ............................................................. 13

2 Classificação do regime de escoamento de acordo com o coeficiente ' $x$ ' da equação potencial, representativa da relação vazão versus pressão ............................ 14

3 Classificação da uniformidade de distribuição de água segundo normas da ABNT...21

4 Função dos pinos do endereço 378 da porta paralela ..............................................25

5 Função dos pinos do endereço 37A da porta paralela ..............................................25

6 Função dos pinos do endereço 379 da porta paralela ..............................................26

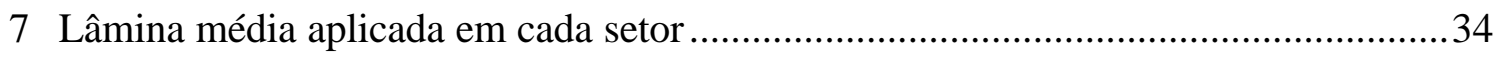

8 Soma total das vazões das agulhas em diversas pressões .........................................36

9 Lista de material e preços da parte estrutural do sistema de irrigação: PU-preço

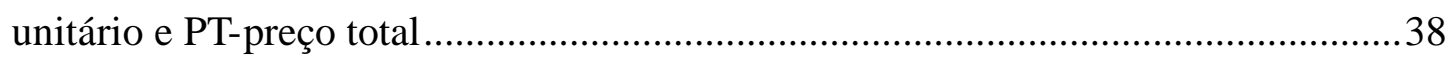

10 Lista de material e preços da parte eletrônica referente a automação do sistema de irrigação: PU-preço unitário e PT-preço total 


\title{
DESENVOLVIMENTO E AVALIAÇÃO DE UM SISTEMA DE IRRIGAÇÃO AUTOMATIZADO PARA ÁREAS EXPERIMENTAIS
}

\author{
Autor: Rodrigo Otávio Rodrigues de Melo Souza \\ Orientador: Prof. Dr. Tarlei Arriel Botrel
}

\section{RESUMO}

Visando obter uma irrigação eficiente, precisa e de baixo custo operacional, este trabalho teve como objetivo desenvolver, automatizar e avaliar um sistema de irrigação para áreas experimentais. O presente trabalho foi conduzido no campo experimental e no Laboratório de Hidráulica do Departamento de Engenharia Rural da ESALQ, onde um sistema mecanizado e automatizado de irrigação, constituído de uma linha de emissores (agulhas) que se move em linha reta, irrigando basicamente uma faixa retangular, foi desenvolvido e avaliado. A etapa de desenvolvimento do sistema automatizado visou estabelecer e verificar a metodologia de funcionamento, além de especificar todos os seus componentes. Na etapa de avaliação, foram determinados a uniformidade de distribuição de água do sistema, o coeficiente de variação de fabricação e a relação vazão versus pressão dos emissores. Para automação do sistema foi utilizado um computador, que controla a movimentação do equipamento e o acionamento das válvulas de água e fertilizante. Este controle é feito por meio de um programa, criado no ambiente de programação Delphi. As válvulas utilizadas para o controle da irrigação e da injeção de fertilizante são solenóides comumente utilizados em máquinas de lavar roupas. O sistema de irrigação proposto foi desenvolvido e avaliado, executando todas suas funções corretamente, obedecendo a comandos enviados via computador. $\mathrm{O}$ 
programa desenvolvido no ambiente Delphi, além de comandar com precisão um sistema de irrigação, possui outras vantagens, tais como: possibilidade de utilização em computadores obsoletos, facilidade de programação e personalização do programa, o que atende ao interesse específico de cada situação de projeto. A avaliação mostrou que o sistema apresentou boa uniformidade de distribuição de água, de acordo com a classificação NBR 14244, e bom coeficiente de variação de fabricação dos emissores (agulhas), de acordo com a classificação PNBR 12:02-08-022. Por análise de regressão, foi obtida a seguinte expressão, que representa a relação vazão versus pressão das agulhas: $\mathrm{q}\left(\mathrm{L} \mathrm{h}^{-1}\right)=5,3834 \cdot \mathrm{H}(\mathrm{kPa})^{0,7749}$. 


\title{
DEVELOPMENT AND EVALUATION OF AN AUTOMATIZED IRRIGATION SYSTEM FOR EXPERIMENTAL AREAS
}

\author{
Author: Rodrigo Otávio Rodrigues de Melo Souza \\ Adviser: Prof. Dr. Tarlei Arriel Botrel
}

\section{SUMMARY}

The purpose of this study was to develop, automatize and evaluate an irrigation system for experimental areas in order to obtain efficient and precise irrigation at low operational costs. The work was carried out in the experimental field as well as at the Hydraulics Laboratory of the Rural Engineering Department/ESALQ, where a mechanized and automatized irrigation system, consisting of a row of emitters (needles) moving in a straight line, basically irrigating an rectangular area, was developed and evaluated. The developmental stage of the automatized system aimed at establishing and verifying the operation methodology, besides specifying all its components. During the evaluation stage, the water distribution uniformity in the system, the manufacturing variation coefficient as well as the relationship between water flow and emitters pressure were determined. A computer was used to automatize the system, controlling its movements and its water and fertilizer valves. A software manufactured in Delphi environment was used for this control. Solenoid valves, commonly used in washing machines, were employed for controlling the irrigation and the fertilizer injection. The irrigation system suggested was developed and evaluated, performing all its operations correctly, following the commands sent by the computer. The software designed in Delphi environment, besides precisely controlling an irrigation system, shows the 
additional advantages of running on obsolete computers as well as being easily programmed and personalized, attending specific requirements of each project. The evaluation results showed that the system presented good water distribution uniformity, according to the NBR 14244 classification, as well as good manufacturing variation coefficient for the emitters (needles), according to the PNBR 12:02-08-022 classification. The following expression representing the water flow vs. pressure in the needles was obtained through regression analysis: $\mathrm{q}\left(\mathrm{L} \mathrm{h}^{-1}\right)=5,3834 \cdot \mathrm{H}(\mathrm{kPa})^{0,7749}$. 


\section{INTRODUÇÃO}

Com a modernização do setor agrícola, tem havido migração de mão-de-obra para o setor urbano-industrial, que nos últimos anos não conseguiu absorver plenamente os excedentes de mão-de-obra agrícola. Esse fenômeno acelera o processo migratório rural-urbano, em busca de emprego e maiores salários.

O deslocamento de pessoas do meio rural para o meio urbano, na busca de melhores oportunidades de emprego, provoca uma escassez de mão-de-obra no setor agrícola. Segundo IBGE (1996), 31,5\% da população economicamente ativa (PEA) do

meio rural são trabalhadores sem instrução, ou seja, com menos de um ano de escolaridade. A falta de mão-de-obra, aliada ao baixo nível educacional da população economicamente ativa do meio rural, faz com que os produtores rurais optem por alternativas que tornem o trabalho no campo mais produtivo, ou seja, um menor número de pessoas trabalhando por unidade de área.

Uma alternativa para tornar o trabalho mais produtivo no campo é a modernização dos processos necessários ao desenvolvimento das atividades agrícolas. Atualmente, a irrigação conta com técnicas modernas, capazes de substituir o trabalho do homem. Portanto, existem hoje no mercado inúmeros equipamentos de qualidade, que automatizam e facilitam a utilização de sistemas de irrigação. Um exemplo é o controlador de irrigação, que comanda válvulas eletromagnéticas e aciona o conjunto motobomba, entretanto, o custo dessas válvulas e controladores pode tornar a automação do sistema inviável para pequenas áreas.

Além disso, em função da iminente cobrança pelo uso da água, elevação dos custos de energia e mão-de-obra, e ainda devido ao surgimento de computadores e outros equipamentos eletrônicos, tem-se notado um fator comum, que é a automatização 
de sistemas de irrigação. No Brasil, pelos mesmos fatores, uns com maior ou menor grau de importância do que outros, já existe o interesse, e mesmo alguns casos, de utilização de sistemas automáticos ou semi-automáticos.

A agricultura irrigada, assim como as demais atividades do meio rural, necessitam acompanhar os avanços tecnológicos. Nas últimas décadas, os aparelhos eletrônicos e os computadores estão num crescente avanço tecnológico, tornando-se mais baratos, precisos, manuseáveis e com melhor interface ao usuário.

$\mathrm{Na}$ indústria eletrônica existem muitos componentes, sensores e microcontroladores que podem ser úteis à irrigação. Cabe aos técnicos da área identificar como e onde esses avanços podem ser utilizados.

O computador pessoal (PC), equipamento de uso bastante difundido, pode ser utilizado como um controlador de irrigação, que pode comandar válvulas solenóides, acionar motobombas, além de armazenar dados, isso tudo através das portas de comunicação externa. A grande vantagem de sua utilização é a personalização das atividades, ou seja, o usuário pode elaborar um programa computacional que atenda às suas necessidades específicas, além de poder utilizar um computador obsoleto para realização dessas atividades.

As vantagens desse equipamento automático sobre o operador humano são, em geral: custo, assiduidade, rapidez, precisão; sua desvantagem é a incapacidade para reagir a perturbações e acidentes, além daqueles previstos em seu projeto.

Nesse sentido, visando obter uma irrigação eficiente, precisa e de baixo custo operacional, este trabalho teve como objetivo desenvolver, automatizar e avaliar um sistema de irrigação com movimentação linear para áreas experimentais. 


\section{REVISÃO DE LITERATURA}

\subsection{Eletrônica e automação}

Para que um país em desenvolvimento possa alcançar níveis de produtividade do trabalho comparáveis com os de países desenvolvidos, é necessária a utilização de tecnologias que diminuam o requerimento de mão-de-obra por unidade de área. Essa redução deve ocorrer naturalmente quando o setor urbano-industrial é capaz de absorver a mão-de-obra excedente. Nos países em desenvolvimento, a força de trabalho agrícola costuma aumentar mais rapidamente que a demanda do setor não-agrícola por esse fator. Por outro lado, o aumento da produtividade da mão-de-obra agrícola pode ser alcançado com investimentos em educação e inovações tecnológicas que permitam utilizar com maior eficiência os fatores convencionais, terra e trabalho (Freire, 2000).

Grande parte das inovações tecnológicas tem como princípio básico dispositivos eletrônicos. Ao longo dos últimos anos, a eletrônica vem passando por uma evolução extremamente rápida, ocupando uma posição de destaque entre todas as outras tecnologias (Braga, 1999).

Antigamente aprendia-se como funcionava um transistor porque televisores, rádios e amplificadores usavam esse componente e, para consertá-los, montá-los ou projetá-los, era preciso conhecê-lo. Hoje em dia, os computadores usam circuitos integrados muito complexos, que contêm milhões de transistores, o que significa que para saber como funciona um computador é ainda necessário saber como o transistor opera. A aplicação final mudou, mas a base continua: sem a eletrônica básica é impossível saber como funcionam os dispositivos de alta tecnologia de hoje (Braga, 1999). 
A eletrônica tem um papel fundamental na modernização das atividades agrárias, a qual possibilita a automação dos equipamentos, tornando as atividades mais rápidas e precisas.

A automação de processos tem sido, neste século, uma tecnologia de profunda repercussão, cuja importância provém não só de substituir o trabalho humano nas tarefas monótonas e/ou cansativas, mas também, e principalmente, do fato de permitir sensível melhoria na qualidade dos processos, com pequena elevação no custo do equipamento (Castrucci, 1969).

Todo sistema automático necessita de uma central de controle, na qual está armazenada a programação que comanda todas as funções do equipamento. Uma central de controle de fácil acesso e baixo custo é o computador pessoal, que é capaz de comandar equipamentos enviando sinais através das portas de comunicação da CPU.

A comunicação é feita com o meio externo através de dispositivos acessados pela CPU, com endereçamentos (portas). Um PC geralmente possui como configuração básica dois tipos de portas: a) Paralela: usada principalmente por periféricos de acesso local que exigem maior capacidade de tráfego de informações, como impressoras e scanners; b) Serial: usada principalmente por periféricos de acesso a longas distâncias (via linha telefônica/MODEM), ou dispositivos que exigem menor tráfego de informações, como é o caso do mouse (Vilela, 1999).

Os sistemas de automação têm grande potencial de uso na agropecuária e são utilizados na agricultura e zootecnia de precisão para automatizar processos, monitorar melhor os sistemas, otimizar a produção e reduzir perdas (Silva, 1998).

Segundo Gornat \& Silva (1990), a automatização do sistema de irrigação apresenta as seguintes vantagens:

a) Melhor administração da propriedade ou projeto agrícola: controle centralizado, tomada de decisão automática, monitoração ou supervisão da operação do sistema, obtenção do histórico completo das aplicações de água e fertilizantes;

b) Obtenção de maiores produtividades a um menor custo: controle preciso do tempo de aplicação da irrigação, irrigações sob condições ótimas, medições precisas das quantidades de água e fertilizante; 
c) Economia de mão-de-obra: abertura e fechamento automático de válvulas e registros, operação automática de bombas de recalque e de reforço;

d) Economia de água;

e) Economia de energia;

f) Economia de fertilizante: quantidades administradas de forma precisas, solução balanceada apropriadamente.

Um sistema automático bem elaborado pode responder às situações de adversidade de forma inteligente, evitando que o problema se agrave. Em último caso, um sistema de alarme pode ser acionado para chamar a atenção do produtor para possíveis problemas. Mesmo que o produtor esteja ausente da propriedade, é possível, por exemplo, que um sistema mais sofisticado disque para um aparelho de telefone automaticamente e anuncie uma das mensagens pré-definidas, alertando o produtor ou responsável de plantão a respeito do tipo de ocorrência (Fialho, 1999). Além disso, a automação permite monitorar e controlar o funcionamento de um sistema físico de forma segura, rápida e automática. Este controle visa monitorar tarefas rotineiras, reagindo a certas características previsíveis do ambiente (Silva, 2000).

Existem inúmeros exemplos de sistemas de automação de aquisição de dados com os mais variados graus de complexidade. Todos eles, entretanto, têm alguns pontos comuns que os caracterizam. Na maioria dos casos, também é necessário pelo menos um controlador inteligente e possivelmente um meio pelo qual diferentes unidades do sistema possam se comunicar entre si e com o meio externo (Fialho, 1999).

Dodi (1990) construiu um sistema coletor automático para ensaio de microaspersores, utilizando transdutores em substituição aos coletores adicionais. Estes transdutores, quando alimentados por um circuito oscilador, geram um sinal elétrico proporcional à grandeza medida (nível líquido). O sinal fornecido a um sistema de aquisição de dados a partir do interfaceamento A/D possibilita a avaliação do perfil de distribuição, bem como a uniformidade de distribuição de água aplicada por um microaspersor. A calibração desse sistema é bem abrangente, permitindo tanto o seu uso 
na avaliação da uniformidade de distribuição em sistemas de irrigação como em qualquer outro sistema que necessite da leitura da lâmina d'água.

O monitoramento automático para manejo de irrigação, embora ainda incipiente no Brasil, constitui uma ferramenta importante no controle das aplicações de água para as plantas e uma maior eficiência do seu uso, assegurando a sustentabilidade do sistema agrícola irrigado e a preservação do meio ambiente. Nos sistemas de irrigação em jardins é comum a adoção de controle automático da irrigação com o uso do temporizador eletrônico, equipamento que promove a abertura ou o acionamento de motobombas em períodos de tempo predeterminados. Entretanto, esses equipamentos não levam em consideração o teor de água do solo ou outra variável do sistema soloplanta-atmosfera. Sistemas automáticos utilizando o tensiômetro existem comercialmente no mercado, porém em pequena escala. O desenvolvimento dessa metodologia constitui uma linha de pesquisa e extensão no sentido de sempre contribuir para o advento de equipamentos eficientes no controle de irrigação com baixo custo e acessível a agricultores (Carvalho et al., 2001).

\subsection{Avaliação do sistema}

\subsubsection{Uniformidade de distribuição de água}

Sistemas de irrigação, além de serem importantes para áreas de produção com precipitação irregular durante o ciclo das culturas, também o são para a pesquisa agrícola. Nesse caso, a precisão e a adaptabilidade do sistema são fatores preponderantes, devido principalmente ao grande número de parcelas experimentais em escala reduzida a serem implantadas com tratamentos diferenciados (Rocha et al., 1998).

Silva et al. (1997) afirmaram que freqüentemente é necessário avaliar o desempenho de um sistema de irrigação, a fim de determinar sua aplicabilidade em certas condições.

Um sistema de irrigação pode ser avaliado levando-se em conta aspectos técnicos (eficiência e uniformidade) e aspectos econômicos. 
Uma análise da qualidade da irrigação, ou seja, da performance técnica do sistema, só é possível quando são associados os conceitos de eficiência com medidas de uniformidade, adequabilidade da irrigação e perdas. Evidentemente, deve-se estabelecer a relação custo/benefício entre a qualidade da irrigação e o valor econômico da cultura (Sales, 1997).

A eficiência de aplicação de água é definida pela relação entre a quantidade de água incorporada ao solo, até a profundidade efetiva do sistema radicular da cultura, e a quantidade de água aplicada.

A eficiência é um parâmetro muito usado no dimensionamento e manejo de sistemas de irrigação. Segundo Keller (1984), ela pode ser dividida em dois componentes: uniformidade de distribuição e perdas de água.

A uniformidade de distribuição de água é um importante parâmetro a ser determinado para obtenção de melhor eficiência de irrigação.

A uniformidade é uma característica que pode ser usada para comparar diferentes sistemas. Um sistema de irrigação que aplica uma lâmina média adequada, porém com pequena uniformidade, certamente propiciará a formação de subáreas irrigadas com excesso de água aplicada e outras com déficit.

Segundo Silva et al. (1997), sistemas com baixa uniformidade exigem maiores lâminas d'água, para assegurar que a quantidade de água necessária seja distribuída por toda a área. Muitos sistemas do tipo pivô central são usados para aplicação de produtos químicos no solo, via água de irrigação; nesses casos, pequena uniformidade de distribuição poderia resultar em danos para as culturas, em função da aplicação excessiva ou deficiente do produto químico.

Uma das etapas básicas quando da implantação ou manejo de um projeto de irrigação é a determinação da uniformidade de distribuição de água de irrigação, pois ela é o melhor indicativo da qualidade da irrigação. Via de regra, a uniformidade de aplicação da água de irrigação é quantificada por meio dos coeficientes de uniformidade (Rodrigues et al., 1997).

Christiansen (1942) propôs a quantificação da distribuição das precipitações por um coeficiente que utiliza os desvios absolutos em relação à média, expresso pela eq.(1): 


$$
C U C=100\left[1-\left(\frac{\sum_{i=1}^{n}|X i-X|}{\sum_{i=1}^{n} X i}\right)\right]
$$

onde:

CUC - coeficiente de uniformidade de distribuição de água de Christiansen;

$\mathrm{Xi}$ - precipitação coletada no pluviômetro de ordem $\mathrm{i}$;

$\mathrm{X}$ - média geral das precipitações coletadas nos pluviômetros;

n - número de pluviômetros.

Esse coeficiente é universalmente conhecido e seus valores servem de referência na avaliação de um equipamento de irrigação (Silva et al., 1997).

A determinação do coeficiente de uniformidade é o processo estatístico mais comum para avaliação de sistemas de irrigação por aspersão, sendo que, por convenção, $80 \%$ é o valor mínimo aceitável para o desempenho normal do aspersor (Gomide et al., 1980).

Para cultivos com sistema radicular médio, o sistema de aspersão deve apresentar CUC de $82 \%$ a $88 \%$. No caso de árvores frutíferas com sistema radicular profundo, em que a irrigação é suplementar, a uniformidade mais econômica pode variar de $70 \%$ a 80\% (Sales, 1997).

Hart (1961) propôs o Coeficiente de Hart (UH), expresso pela eq.(2):

$$
U H=1-0,797\left(\frac{D P}{M G}\right)
$$

onde:

UH - coeficiente de uniformidade de distribuição de água de Hart;

DP - desvio-padrão;

MG - média geral.

Segundo Coelho (1990), caso os valores coletados sigam uma distribuição normal, então o valor do CUC é igual ao valor do UH.

Também, segundo Coelho (1990), outro coeficiente de uniformidade de distribuição de água frequentemente utilizado é o de Kruse (1978), expresso pela relação entre a média das 25\% menores precipitações (MEP) e média geral (MG), eq.(3): 


$$
U D=\frac{M E P}{M G}
$$

Vários fatores influem na distribuição da água nos sistemas de irrigação por aspersão, podendo ser agrupados em fatores climáticos, fatores aerodinâmicos e fatores ligados ao aspersor, ao sistema de distribuição e ao manejo do sistema (Gomide et al., 1980).

Devido à importância da escolha de um coeficiente que seja sensível às variações operacionais, tão comuns nos sistemas de irrigação, é que Rodrigues et al. (1997) realizaram uma pesquisa visando avaliar a sensibilidade de alguns coeficientes de uniformidade a mudanças nos fatores operacionais. Os coeficientes utilizados foram:

a) Benami \& Hore (1962)

$$
A=166 \frac{N a}{N b}\left[\frac{2 T b+D b \cdot M b}{2 T a+D a \cdot M a}\right]
$$

onde:

A - coeficiente de uniformidade de distribuição de água de Benami e Hore;

$\mathrm{D}_{\mathrm{a}}$ - diferença entre o número de dados de precipitação abaixo e acima de $\mathrm{M}_{\mathrm{a}}$;

$\mathrm{D}_{\mathrm{b}}$ - diferença entre o número de dados de precipitação abaixo e acima de $\mathrm{M}_{\mathrm{b}}$.

$\mathrm{M}_{\mathrm{a}}$ - média do grupo de dados de precipitação acima da média geral;

$\mathrm{M}_{\mathrm{b}}$ - média do grupo de dados de precipitação abaixo da média geral;

$\mathrm{N}_{\mathrm{a}}$ - número de dados de precipitação acima da média geral;

$\mathrm{N}_{\mathrm{b}}$ - número de dados de precipitação abaixo da média geral;

$\mathrm{T}_{\mathrm{a}}$ - soma dos dados de precipitação acima de $\mathrm{M}_{\mathrm{a}}$;

$\mathrm{T}_{\mathrm{b}}$ - soma dos dados de precipitação abaixo de $\mathrm{M}_{\mathrm{b}}$;

b) Wilcox \& Swailes (1947) 


$$
C U E=100\left(1-\frac{S d}{X}\right)
$$

onde:

CUE - coeficiente de uniformidade de distribuição de água de Wilcox e Swailes;

Sd - desvio-padrão dos dados de precipitação;

$\mathrm{X}$ - média geral dos dados de precipitação.

c) Karmeli (1978)

$$
U C L=1-0,25 . b
$$

onde:

UCL - coeficiente de uniformidade de distribuição de água de Karmeli;

b - coeficiente de regressão.

d) Christiansen (1942), eq.(1).

e) Hart (1961), eq.(2).

f) Serviço de Conservação de Solos dos Estados Unidos (Kruse, 1978), eq.(3).

Com os resultados obtidos, Rodrigues et al.(1997) concluíram que o coeficiente A, proposto por Bernami \& Hore (1962), foi o coeficiente mais sensível às mudanças dos fatores operacionais. O CUC, proposto por Christiansen, o $\mathrm{UCH}$, proposto por Hart, e o UCL, proposto por Karmeli, foram os coeficientes menos sensíveis a essas mudanças.

A determinação da uniformidade de distribuição é feita em testes utilizando-se um ou mais emissores, dispondo ao seu redor um número suficiente de pluviômetros para que no mínimo 50 recebam água. Tais pluviômetros devem estar regularmente espaçados e captar a lâmina aplicada em um tempo de funcionamento superior a 1 hora ou suficiente para aplicação de 5mm de lâmina (Frizzone, 1992). 
Keller \& Bliesner (1990), citados por Mundim (1996), apresentam uma compreensão prática das implicações da uniformidade de distribuição de água. Citam uma combinação de uniformidade de distribuição com área adequadamente irrigada para fornecer a eficiência de distribuição, apresentando as relações em forma de uma tabela, válida para valores de CUC quando a distribuição de água segue um padrão normal. Por exemplo: para um CUC de $80 \%$, supondo-se que se deseje irrigar adequadamente $75 \%$ da área, tem-se que a eficiência de distribuição seria $83 \%$, ou seja, para cada 1mm de lâmina que se deseja aplicar ao solo, deve-se aspergir 1/0,83=1,2 mm de água. Já com um sistema que forneça CUC de 70\%, para irrigar adequadamente o mesmo percentual da área, ter-se-ia uma eficiência de aplicação de 75\%, ou seja, seriam necessários $1 / 0,75=1,33 \mathrm{~mm}$ de água, ou aproximadamente $11 \%$ a mais.

Rezende (1992) considera a uniformidade de distribuição um parâmetro de comparação entre sistemas. Dentre dois que distribuíam a mesma lâmina, o mais uniforme será mais eficiente.

Um fator que está diretamente associado à uniformidade de distribuição de água é a produção das culturas. Em geral, sistemas que possuem emissores com espaçamentos reduzidos aplicam água mais uniformemente, proporcionando maiores produções, embora os custos sejam maiores.

Solomon (1984) afirma que, em alguns casos, a produção pode ser expressa como função da uniformidade e eficiência de irrigação.

Segundo Coelho (1990), quanto maior a uniformidade de distribuição de água menor será a queda de produção da cultura. $\mathrm{O}$ mesmo autor verificou que em valores de CUC superiores a 0,8 existe uma variabilidade pequena em termos de queda de produção e em valores inferiores a 0,8 existe uma maior variabilidade em queda de produção (um mesmo valor de CUC pode apresentar diferentes valores de queda de produção). As culturas em estudo foram batata, feijão e trigo.

Percebe-se que a uniformidade ótima para um projeto depende das condições locais e de preços do produto e de insumos, podendo-se utilizar valores menores que os tradicionais de projeto quando há restrição na quantidade de água disponível (Mundim, 1996). 


\subsubsection{Coeficiente de variação de fabricação}

No dimensionamento de sistemas de irrigação, deve-se considerar a variabilidade existente entre os emissores, decorrente do processo de fabricação. A fabricação deverá ser exata, uniforme e constantemente monitorada, pois pequenas variações poderão causar grandes diferenças de vazão (Vieira, 1996).

Solomon (1979) diz que o fato de os emissores usados em irrigação localizada possuírem dimensões reduzidas dificulta a sua construção precisa, fazendo com que a variação de vazão em função da variação na construção dos emissores não possa ser ignorada.

Botrel (1984) acrescenta que pequenas variações nesses orifícios de saída de água (1 a 2mm) provocam grandes diferenças na vazão a uma mesma pressão. Essas diferenças nos orifícios podem ultrapassar a 10\%, tornando-se nesses casos mais importantes que as variações de vazão devidas às diferenças de pressão ao longo da linha lateral.

Keller \& Karmeli (1974) comentam sobre a uniformidade dos sistemas de irrigação, e citam que esta uniformidade depende também da precisão com que os emissores são fabricados.

Solomon (1979) fez diversas considerações que fornecem uma justificativa supondo que as vazões dos emissores, em uma dada pressão, são normalmente distribuídas em função do processo de fabricação.

Assumindo que as diferentes vazões ocasionadas pelos processos construtivos têm distribuição normal, isso permite utilizar os conc eitos de estatística correspondentes a essa distribuição para conclusões quantitativas.

O mesmo autor propôs, então, um coeficiente de variação de fabricação (CVF), dado pela expressão:

$$
C V f=\frac{S}{q m}
$$


em que:

CVf - coeficiente de variação de fabricação (\%);

$\mathrm{S}$ - desvio-padrão da vazão $\left(\mathrm{L} \mathrm{h}^{-1}\right)$;

qm - vazão média de uma amostra adequada de emissores testados a uma pressão normal de operação $\left(\mathrm{L} \mathrm{h}^{-1}\right)$.

Existem diversas classificações de emissores quanto à uniformidade de vazão, como Solomon (1979) e ABNT (1986), apresentadas na Tabela 1 a seguir.

Tabela 1. Classificação da uniformidade de vazão.

\begin{tabular}{lcc}
\hline & CVF (\%) & Classificação \\
\hline Solomon (1979) & Até 3 & Excelente \\
4 a 7 & Média \\
8 a 10 & Marginal \\
11 a 14 & Pobre \\
Acima de 15 & Ruim \\
ABNT(1986) - PNB 12:02.08.-022 & até 10 & Boa \\
& 10 a 20 & Média \\
& 20 a 30 & Marginal \\
& Acima de 30 & Inaceitável \\
\hline
\end{tabular}

O CVF é um importante fator que influencia a uniformidade de emissão de água e, portanto, a eficiência do sistema de irrigação. Segundo Solomon (1979), os valores típicos oscilam entre 0,02 e 0,10, podendo algumas vezes ser observados valores mais elevados.

Torna-se importante, portanto, quando se seleciona um emissor, conhecer o CVF que deve ser fornecido pelo fabricante.

Para a determinação experimental do CVF e da relação vazão versus pressão, a ABNT (1986) estabelece que seja estudada uma amostra de no mínimo 50 unidades para 
gotejadores e 20 para microaspersores, obtidas aleatoriamente na linha de produção do fabricante.

\subsubsection{Relação vazão versus pressão}

A relação entre vazão e pressão é uma característica hidráulica que influencia diretamente o desempenho do sistema. Essa característica é influenciada pelo tipo de emissor, material e processo de fabricação.

Segundo Keller \& Karmeli (1974), a equação que descreve a vazão de emissores pode ser apresentada como segue:

$$
q=k \cdot H^{x}
$$

em que:

q - vazão do emissor $\left(\mathrm{L} \mathrm{h}^{-1}\right)$;

$\mathrm{k}$ - coeficiente específico de cada emissor;

$\mathrm{H}$ - pressão na entrada do emissor $(\mathrm{kPa})$;

$\mathrm{X}$ - constante que caracteriza o regime de escoamento.

Segundo Vieira (1996), por melhores que sejam os processos de fabricação dos emissores, ocorrem diferenças na fabricação, refletindo-se assim nos valores dos coeficientes da equação de fluxo do emissor (k e x).

$O$ expoente ' $\mathrm{X}$ ' da equação potencial representa o regime de escoamento dos emissores. A classificação apresentada por Keller \& Karmeli (1974) pode ser observada na tabela a seguir.

Tabela 2. Classificação do regime de escoamento de acordo com o coeficiente ' $x$ ' da equação potencial, representativa da relação vazão versus pressão.

\begin{tabular}{cc}
\hline Expoente $\mathrm{x}$ & Regime de escoamento \\
\hline $\mathrm{x}=0,5$ & Turbulento \\
$0,5<\mathrm{x}<0,7$ & Parcialmente turbulento \\
$0,7<\mathrm{x}<1,0$ & Instável \\
$\mathrm{x}=1$ & Laminar \\
\hline
\end{tabular}


Solomon (1979) comenta que a redução na vazão é menos influenciada pela variação da pressão à medida que $o$ valor de ' $x$ ' decresce. Os valores de ' $x$ ' relacionamse com o regime de escoamento: para regime turbulento, $\mathrm{x}=0,5$, e para regime laminar, $\mathrm{x}=1,0$. 


\section{MATERIAL E MÉTODOS}

O presente trabalho foi conduzido no campo experimental e no Laboratório de Hidráulica do Departamento de Engenharia Rural da ESALQ/USP, onde um sistema mecanizado e automatizado de irrigação, constituído de uma linha de emissores que se move em linha reta, irrigando basicamente uma faixa retangular, foi desenvolvido e avaliado.

A etapa de desenvolvimento do sistema automatizado visou estabelecer e verificar a metodologia de funcionamento, além de especificar todos os seus componentes. Na etapa de avaliação, foram determinados a uniformidade de distribuição de água do sistema, o coeficiente de variação de fabricação e a relação vazão versus pressão dos emissores.

\subsection{Concepção do sistema}

A aplicação de água pelo equipamento é feita por emissores (agulhas) com a especificação $25 \times 8$, cabo verde, comprimento $25 \mathrm{~mm}$ e diâmetro externo de $0,8 \mathrm{~mm}$, que estão igualmente espaçados ao longo de um tubo de cobre. Este tubo de apoio tem diâmetro de $22 \mathrm{~mm}$ e comprimento de $1,47 \mathrm{~m}$, possui 24 agulhas espaçadas em $5 \mathrm{~cm}$, e se desloca a uma altura média de $85 \mathrm{~cm}$ acima da superfície do solo.

Na extremidade do tubo de apoio foi acoplada uma luva de PVC de 20mm, na qual foi instalada uma conexão de saída para medir pressão na entrada do tubo. $\mathrm{Na}$ sequiência foi conectado um registro de esfera de $16 \mathrm{~mm}$, junto com uma curva de $90^{\circ}$ de PVC e um conector de plástico para mangueira de $16 \mathrm{~mm}$. A água foi injetada no sistema 
utilizando-se uma mangueira flexível de $16 \mathrm{~mm}$ conectada na extremidade do tubo de apoio.

Na extremidade oposta foi acoplado um cap de PVC de 20mm. Eventualmente, antes do início da irrigação, este era retirado com a finalidade de remover o ar presente na água, o qual poderia encontrar-se retido no interior das canalizações do sistema de irrigação.

A distribuição de água aos canteiros foi feita através de uma tubulação de PVC rígido, para instalação predial, de $20 \mathrm{~mm}$ de diâmetro, enterrada na parte central das fileiras de canteiros, no sentido transversal ao seu comprimento.

A tomada d'água, que alimentava individualmente cada canteiro, era composta por uma curva de $90^{\circ}$ de PVC, que foram acopladas as válvulas responsáveis pelo controle do fornecimento de água.

O tubo de apoio foi fixado no centro de uma estrutura retangular de madeira, em cujas extremidades colocaram-se parafusos para funcionarem como eixos de quatro rodas. Estas são de PVC e possuem 7,5cm de diâmetro e 1,4cm de espessura.

Para que a lâmina de irrigação fosse constante ao longo dos canteiros, construiuse um sistema de tracionamento para manter constante a velocidade de deslocamento do equipamento.

O sistema foi tracionado por um motor de corrente contínua de 12 volts, alimentado por bateria. Este motor, foi adaptado a partir de um motor utilizado para movimentar o Impador de pára-brisa do carro. Este traciona o sistema através de um cabo de aço. O cabo está preso no ponto (a) do carrinho, circunda duas vezes a polia do motor, com o objetivo de aumentar o atrito entre ambos, de modo que o carrinho possa movimentar-se nos dois sentidos, sem ocorrência de patinamento indesejável no sistema de tração, passa pela outra polia presa no final do canteiro, e finalmente é preso no ponto (b) do carrinho (Figura1 e Figura 2). O motor foi parafusado em uma chapa de aço em forma de "C", cuja base foi fixada em uma bancada de madeira colocada junto aos dois mourões no início de cada canteiro. Ao eixo do motor foi acoplada uma polia de $2,67 \mathrm{~cm}$ de diâmetro. 
Em sistema de trilho, as rodas se deslocam sobre dois arames de aço espaçados de $1,5 \mathrm{~m}$, devidamente esticados e que ficaram suspensos pela sua fixação em mourões colocados nas extremidades de cada canteiro. O sistema mantinha-se alinhado e suspenso, pois nas rodas havia ranhuras com $0,8 \mathrm{~cm}$ de largura e $0,8 \mathrm{~cm}$ de profundidade.

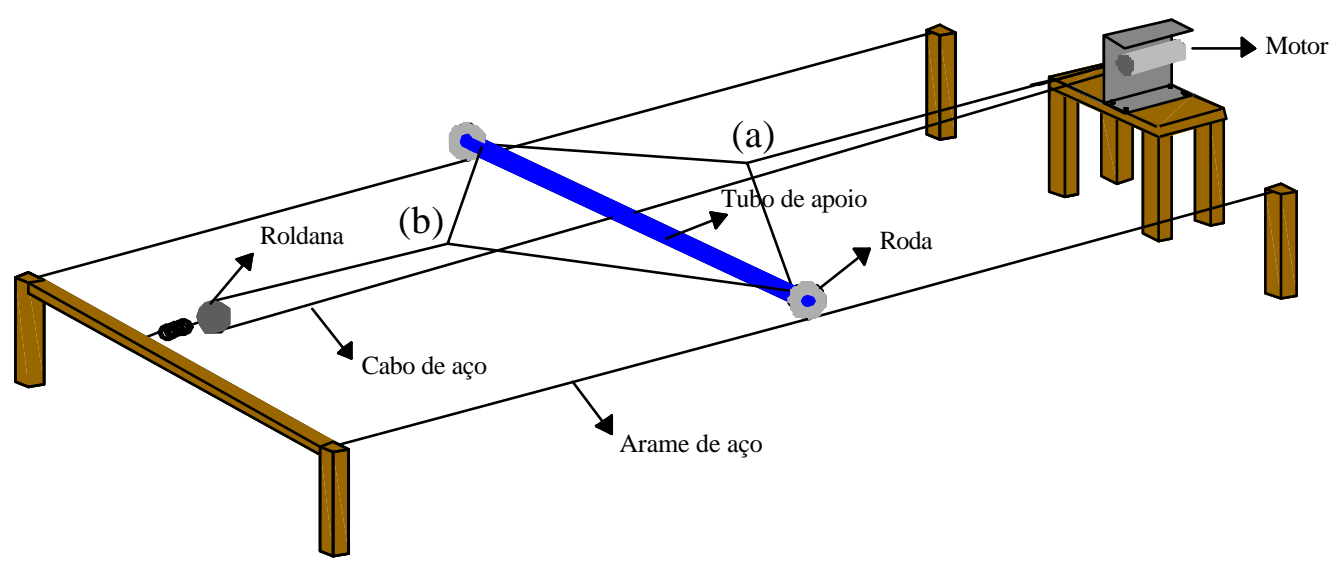

Figura 1 - Esquema em perspectiva do sistema de irrigação.

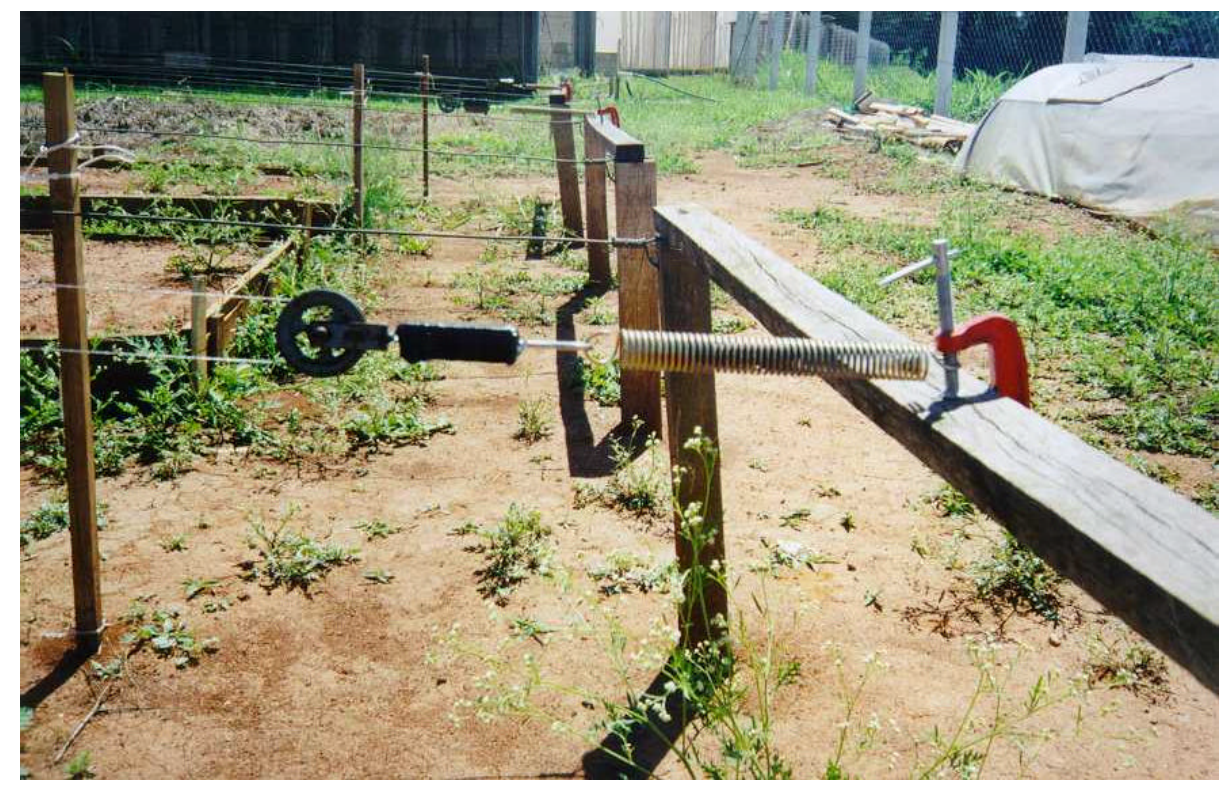

Figura 2 - Vista da roldana no final do canteiro. 
Para automação do sistema foi utilizado um computador. Esse controla o movimento dos carrinhos e o acionamento das válvulas de água e fertilizante. O controle é feito por meio de um programa, criado no ambiente de programação Delphi Versão 3.

Foram desenvolvidos três sistemas iguais e independentes. Cada sistema irriga uma faixa retangular de 15,6m x 1,25m, subdividida em quatro canteiros de $3 \mathrm{~m}$ x 1,25m (Figura 3). Cada canteiro foi cercado por tábuas de madeira com 0,2m de altura.

O comprimento dos canteiros e a largura do equipamento dependem diretamente da capacidade do motor que traciona o sistema. Cabe ao projetista escolher um motor que atenda às necessidades de projeto.

O sistema de movimentação dos carrinhos e alimentação de água e fertilizante mediante a utilização de válvulas solenóides, comumente utilizadas em máquinas de lavar roupas, são iguais para os três sistemas, sendo que o carrinho III não possui válvula que permita a injeção de fertilizante.

A estrutura de campo (canteiros, trilhos de arame e bancada do motor) foi construída para utilização em outro experimento, em que este sistema foi operado manualmente para irrigação de alface, utilizando apenas um carrinho para os três canteiros.

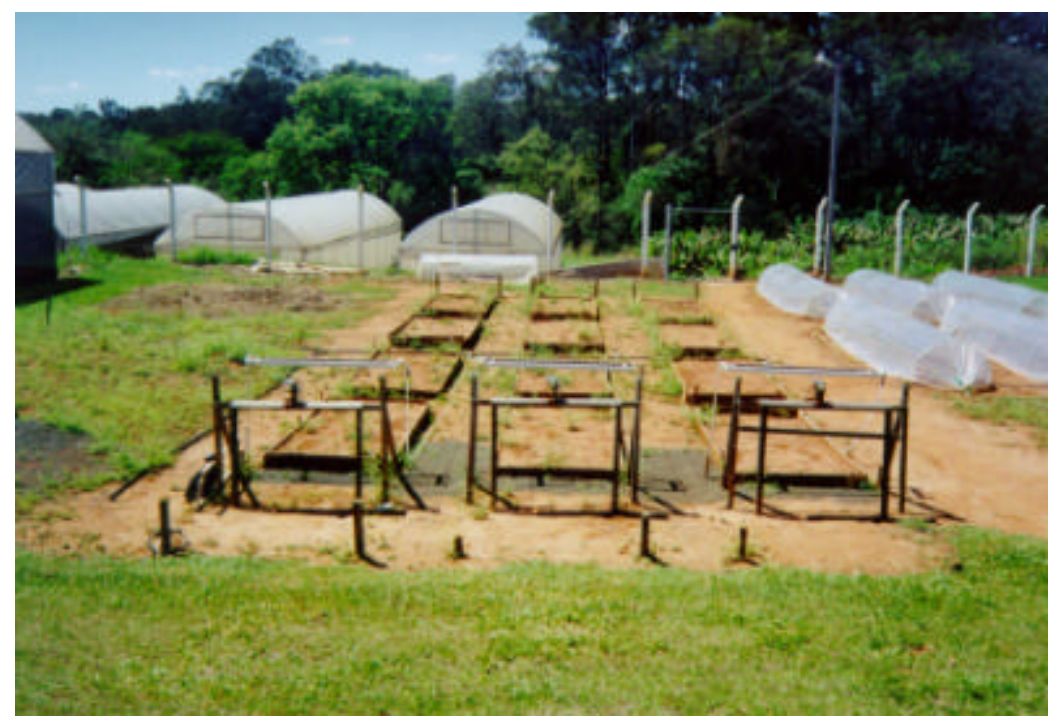

Figura 3 - Vista superior do sistema de irrigação. 


\subsection{Avaliação do sistema}

A avaliação do sistema foi feita pela mensuração da distribuição de água no campo, vazão individual das agulhas e, posteriormente, pelo cálculo do coeficiente de uniformidade do equipamento, coeficiente de variação de fabricação e relação vazão versus pressão dos emissores.

\subsubsection{Uniformidade de distribuição de água}

O coeficiente de uniformidade do equipamento foi calculado com base no Coeficiente de Uniformidade de Christiansen.

Para a determinação da uniformidade de distribuição de água, o equipamento foi colocado em funcionamento, realizando dez passadas sobre uma malha de $13 \times 4$ pluviômetros, o suficiente para que houvesse uma quantidade mínima de água nos coletores de $5 \mathrm{~mm}$. Esse procedimento foi repetido em quatro setores ao longo do canteiro. Para cada setor foi feita a média das quatro fileiras. Sendo assim, o setor fica sendo representado por uma fileira de 13 coletores. O CUC final foi calculado com os valores da malha final resultante da união das fileiras representativas de cada setor (Figura 4).

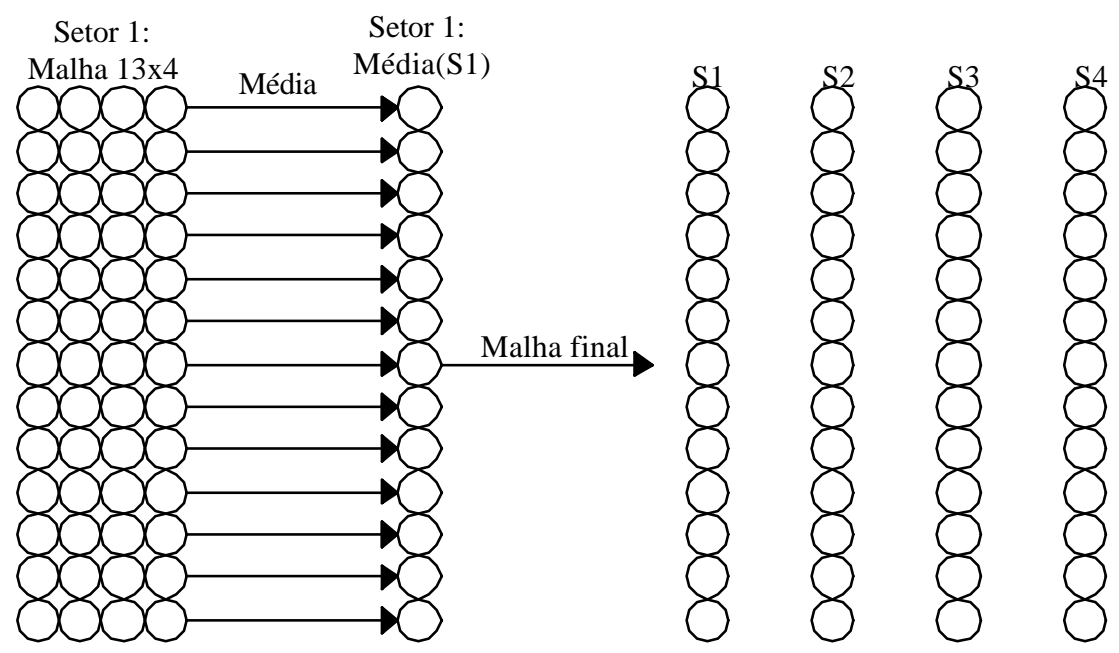

Figura 4 - Esquema de coleta dos dados de precipitação dos pluviômetros para o setor 1. 
Os pluviômetros utilizados para o teste de campo foram compostos de recipientes cilíndricos com área de coleta de $50,4 \mathrm{~cm}^{2}$, e foram espaçados uniformemente ao longo de linhas perpendiculares à direção de caminhamento do carrinho. As linhas de coletores ultrapassaram o comprimento efetivo do sistema.

A pressão da água na entrada do equipamento foi ajustada e mantida em $50 \mathrm{kPa}$ durante o ensaio.

A lâmina coletada foi registrada pela mensuração do volume de água armazenada nos coletores.

O coeficiente de uniformidade foi utilizado como indicativo da performance do equipamento. Para classificação da uniformidade de distribuição de água, foram utilizados os parâmetros apresentados na ABNT, NBR 14244 (1998) (Tabela 3).

Tabela 3. Classificação da uniformidade de distribuição de água segundo normas da ABNT.

\begin{tabular}{cc}
\hline CUC & Uniformidade de distribuição de água \\
\hline Menor que $80 \%$ & Ruim \\
$80 \%$ a $84 \%$ & Regular \\
$85 \%$ a $89 \%$ & Boa \\
Acima de $90 \%$ & Muito boa \\
\hline
\end{tabular}

\subsubsection{Vazão das agulhas}

A uniformidade de vazão das agulhas foi determinada com a mensuração da vazão de sessenta agulhas na pressão de $50 \mathrm{kPa}$. O tempo de coleta foi de 1 minuto para cada repetição. Em seguida, foi calculado o coeficiente de variação de fabricação das agulhas utilizando a eq.(7). 


\subsubsection{Relação vazão versus pressão}

Foi coletado simultaneamente o volume individual dos 12 pares de agulhas de cada carrinho em cinco pressões de serviço diferentes (20, 30, 40, 50 e 60kPa). O tempo de coleta foi de 1 minuto para cada repetição, sendo três repetições por carrinho. Cada carrinho possui 24 agulhas (Figura 5).

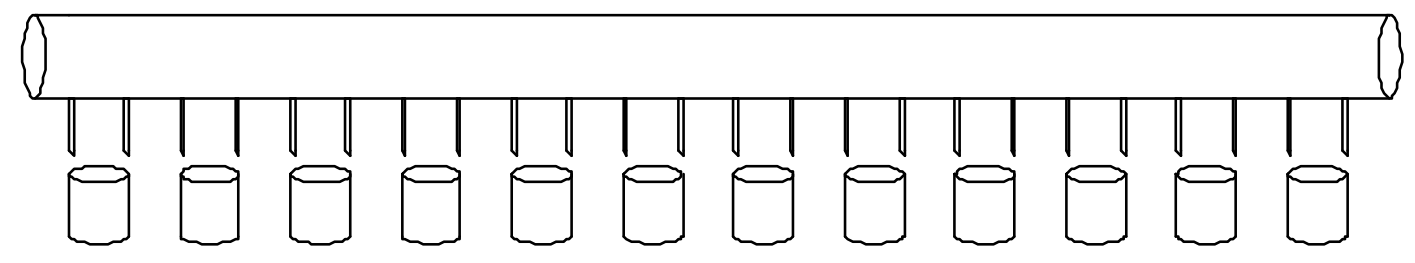

Figura 5 - Esquema de coleta dos dados de vazão

A relação vazão versus pressão das agulhas foi obtida pelo ajuste da equação potencial com pares de valores médios de vazão e pressão. 


\section{RESULTADOS E DISCUSSÃO}

\subsection{Caracterização do sistema}

\subsubsection{Comunicação com a porta paralela do computador}

Os acionamentos das válvulas e dos motores foram feitos via computador, ou seja, através da comunicação com a porta paralela do computador pessoal (PC) (Figura $6)$.

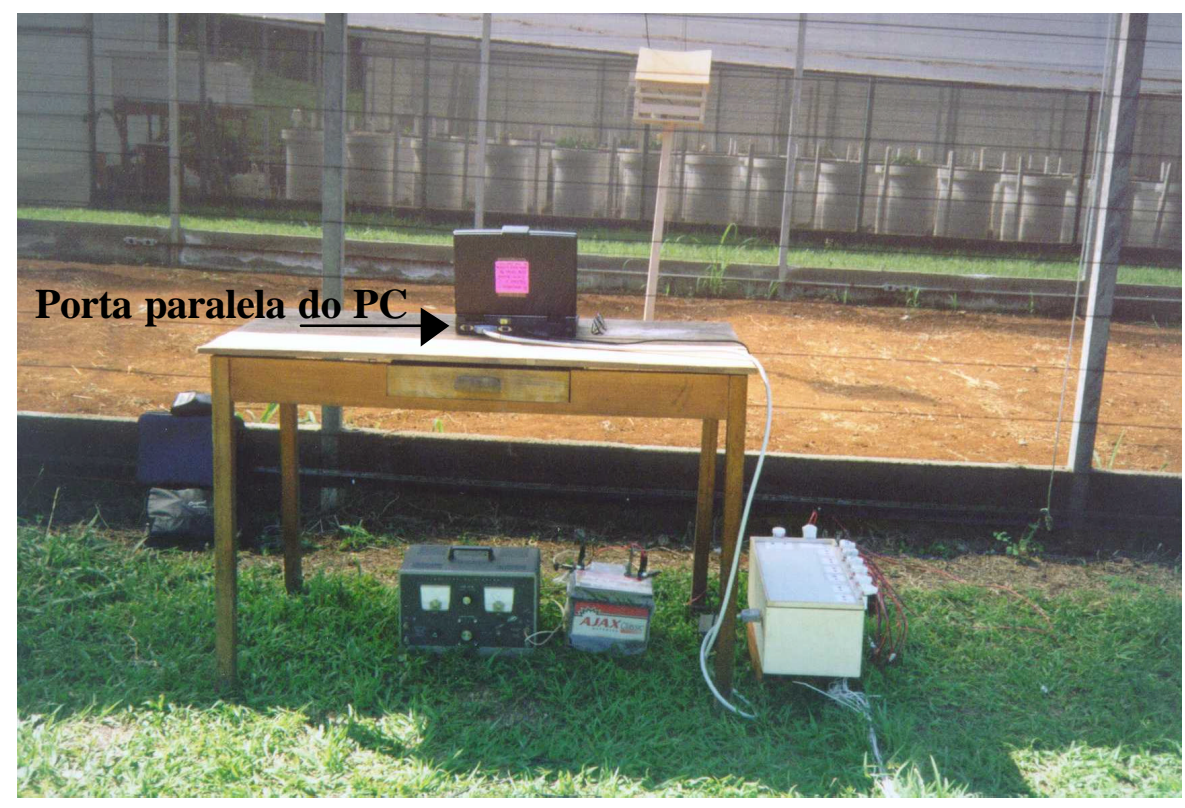

Figura 6 - Vista da comunicação entre computador e meio externo via porta paralela.

O computador utiliza a linguagem binária; portanto, a comunicação entre ele e o meio externo é feita pela da combinação dos dígitos 1 e 0 . Quando um pino da porta 
paralela do computador está energizado com $5 \mathrm{v}$, significa que o pino está no nível alto, representado pelo dígito 1. Quando o pino não está energizado (0v), significa que está no nível baixo, representado pelo dígito 0 .

A porta paralela do computador pode ser controlada pelo ambiente de programação Delphi, que possibilita acesso a porta de comunicação, ou seja, identificação do estado dos pinos (nível alto ou baixo) e controle de seu nível.

A característica de transmitir ou receber dados de forma paralela, isto é, ler ou escrever até 8 bits simultaneamente, torna o uso da porta paralela mais cômodo para aplicações em que não se requerem acessos a grandes distâncias.

A porta paralela (conexão para impressora) é um dispositivo de acesso externo relativamente fácil via programação, disponibilizando 8 bits de saída, 5 bits de entrada e outros 4 bits que podem operar como entrada ou saída.

Nesse experimento foram utilizados todos os bits da porta paralela. A função de cada bit pode ser vista nas Tabelas 4, 5 e 6; e na Figura 7 está a numeração dos pinos da porta paralela do PC.

Os sinais são enviados no endereço 378 através dos bits. Escrever $1 \mathrm{em}$ um bit resulta em nível alto na saída, ou seja, 5 volts. Através destes $5 \mathrm{v}$ pode-se, por exemplo, enviar sinal para ligar e desligar um relé.

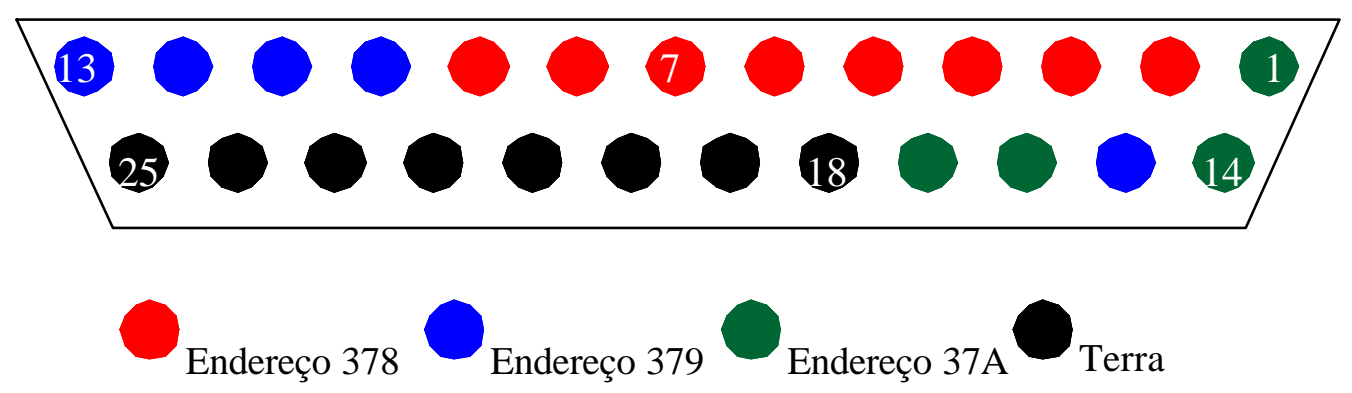

Figura 7 - Conector DB25 fêmea. Numeração dos pinos da porta paralela do PC. 
A leitura do endereço 379 reflete o estado dos 5 bits desse registrador. Dessa forma, é possível acessar o estado de um conjunto de chaves externas; pode-se realizar a leitura de 5 bits de um conversor A/D que monitora um processo, enfim, levar a informação para dentro do PC e processá-la convenientemente.

Os pinos do endereço 37A podem ser utilizados como entrada ou saída. Para utilizar como saída, basta escrever no endereço 37A os 4bits disponíveis. Para utilizar como entrada, deve-se primeiramente fazer a escrita de forma a se ter nível alto $(5 \mathrm{~V}) \mathrm{em}$ todos os 4 pinos de saída, ou seja, nível alto no bit $\mathrm{C} 2$ e baixo nos bits $\mathrm{C} 0, \mathrm{C} 1$ e C3, pois a saída desses três últimos são invertidas.

Tabela 4. Função dos pinos do endereço 378 da porta paralela.

\begin{tabular}{ccccc}
\hline Endereço & Pino & BIT & Direção & Função \\
\hline 378 & 2 & D0 & Saída & Abrir válvula de água do carrinho 1 \\
378 & 3 & D1 & Saída & Abrir válvula de fertilizante do carrinho 1 \\
378 & 4 & D2 & Saída & Mover carrinho 1 sentido Leste-Oeste \\
378 & 5 & D3 & Saída & Mover carrinho 1 sentido Oeste-Leste \\
378 & 6 & D4 & Saída & Abrir válvula de água do carrinho 2 \\
378 & 7 & D5 & Saída & Abrir válvula de fertilizante do carrinho 2 \\
378 & 8 & D6 & Saída & Mover carrinho 2 sentido Leste-Oeste \\
378 & 9 & D7 & Saída & Mover carrinho 2 sentido Oeste-Leste \\
\hline
\end{tabular}

Tabela 5. Função dos pinos do endereço 37A da porta paralela.

\begin{tabular}{ccccc}
\hline Endereço & Pino & BIT & Direção & Função \\
\hline 37A & 1 & C0* & Saída & Abrir válvula de água do carrinho 3 \\
37A & 14 & C1* & Saída & Mover carrinho 3 sentido Leste-Oeste \\
37A & 16 & C2 & Saída & Mover carrinho 3 sentido Oeste-Leste \\
37A & 17 & C3* & Entrada & Ler interruptor magnético canteiro 3 \\
\hline
\end{tabular}

\footnotetext{
*Pinos invertidos: 0 = nível alto e 1 = nível baixo.
} 
Tabela 6. Função dos pinos do endereço 379 da porta paralela.

\begin{tabular}{ccccc}
\hline Endereço & Pino & BIT & Direção & Função \\
\hline 379 & 15 & S3 & Entrada & Ler interruptor magnético canteiro 1 \\
379 & 13 & S4 & Entrada & Ler interruptor magnético canteiro 1 \\
379 & 12 & S5 & Entrada & Ler interruptor magnético canteiro 2 \\
379 & 10 & S6 & Entrada & Ler interruptor magnético canteiro 2 \\
379 & 11 & S7* & Entrada & Ler interruptor magnético canteiro 3 \\
\hline
\end{tabular}

*Pinos invertidos: 0 = nível alto e 1 = nível baixo.

\subsubsection{Acionamento das válvulas}

Para o controle do fornecimento de água e fertilizante foram utilizadas válvulas solenóides (Figura 8). Esse tipo de válvula é comumente utilizada em máquinas de lavar roupa e funciona com a voltagem de 110v.

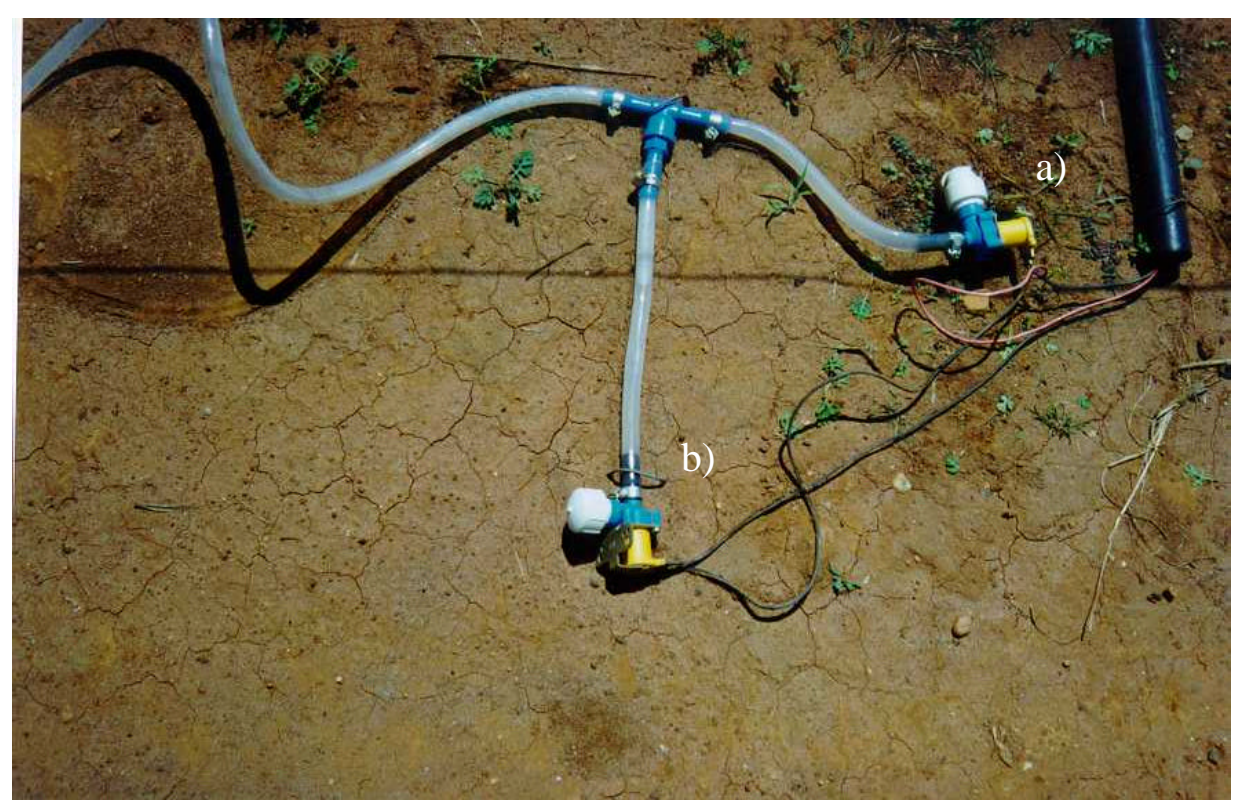

Figura 8 - a) Válvula para injeção de água; b) Válvula para injeção de fertilizante.

Para o acionamento dessa válvula via computador, foram utilizados relés que funcionam como chaves interruptoras (Figura 9). Para ligar o relé, basta excitar a sua 
bobina com 12v. Com o relé ligado, a válvula será aberta, pois um dos fios de alimentação da válvula passará pelo relé.

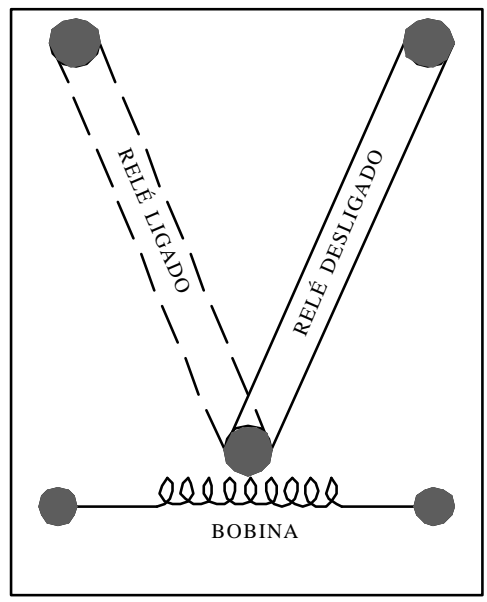

Figura 9 - Esquema do relé para acionamento das válvulas.

O computador envia um sinal de $5 \mathrm{v}$. Este sinal aciona um transistor, que também funciona como um interruptor, deixando passar os 12volts necessários para o acionamento do relé.

O esquema para acionar o relé via porta paralela do computador pode ser visto na figura a seguir.

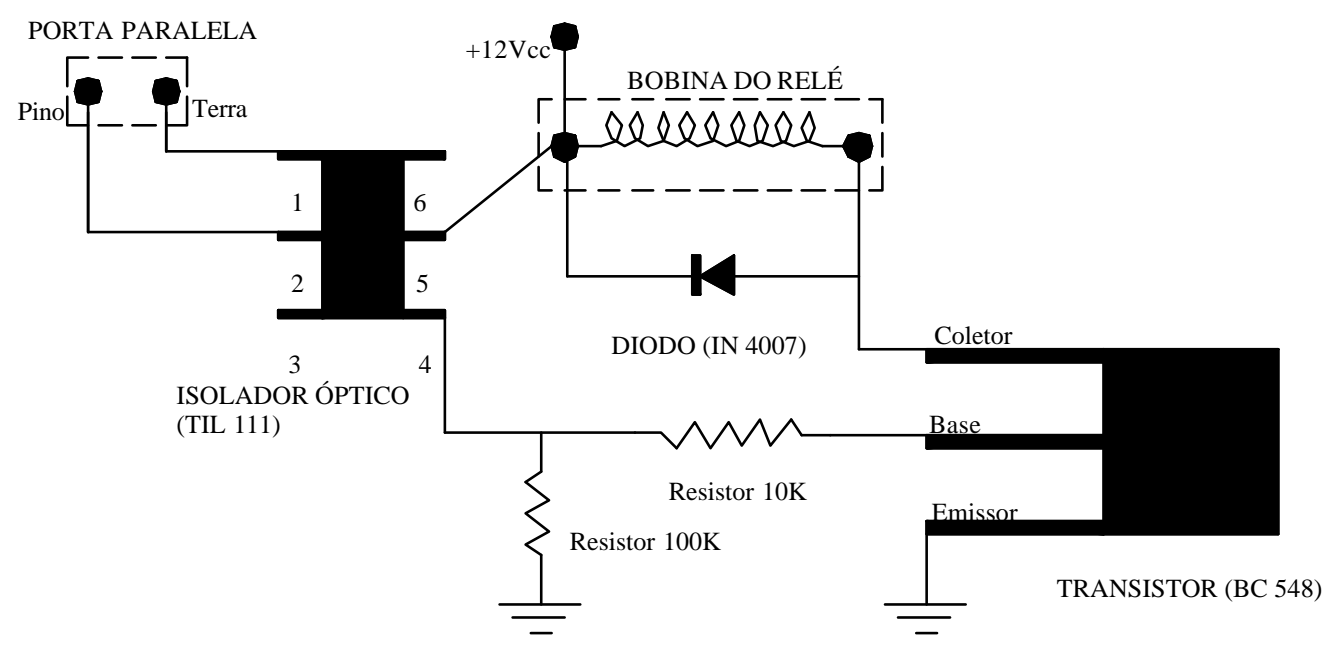

Figura 10 - Esquema elétrico para acionamento do relé via porta paralela do computador. 


\subsubsection{Acionamento dos motores}

O sistema foi tracionado por um motor de corrente contínua de 12 volts, alimentado por bateria (Figura 11).

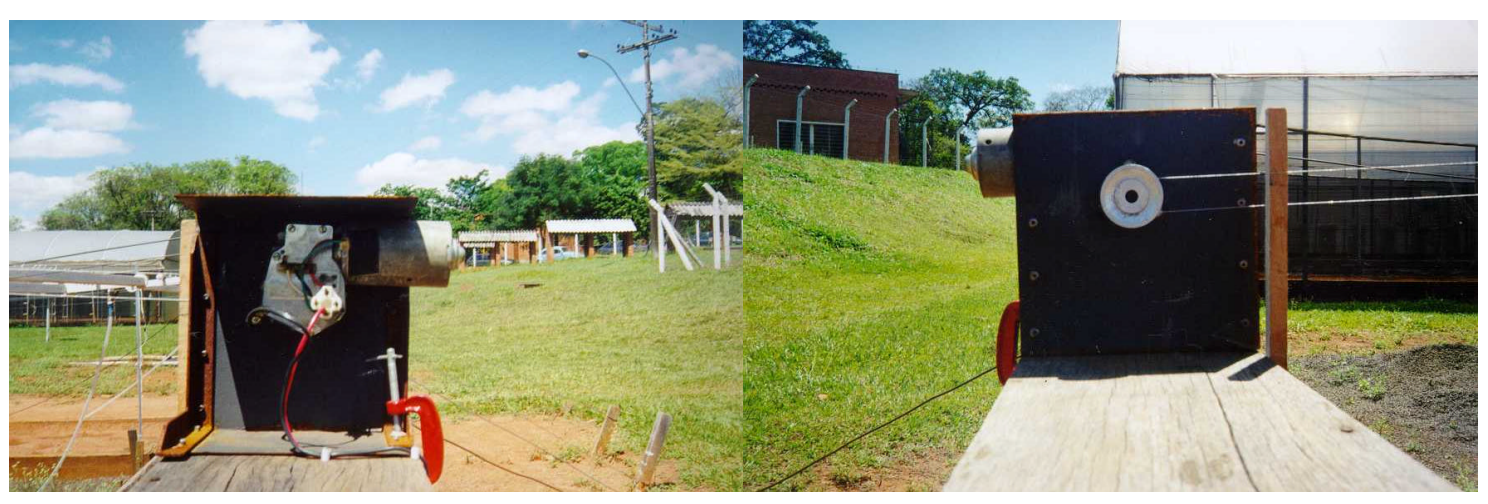

Figura 11 - Motor responsável pela movimentação do sistema.

No acionamento dos motores via computador, foram utilizados relés que funcionam como chaves interruptoras, iguais àqueles do acionamento das válvulas solenóides.

Para que o carrinho mude o sentido de movimentação basta inverter a alimentação do motor, pois quando alimentado com $+12 \mathrm{vec}$ o eixo do motor gira no sentido horário e quando alimentado com $-12 \mathrm{vcc}$ este passa a girar no sentido inverso.

Visando inverter o sentido de rotação dos motores, foram construídos três inversores de polaridade, um para cada motor. A função desse componente é inverter a polaridade de alimentação. Foram utilizados quatro relés para cada inversor, sendo estes acionados via computador. Quando os relés 3 e 4 estão ligados e os relés 1 e 2 desligados, a polaridade mantém-se constante, ou seja, positivo na saída do relé 1 e negativo na saída do relé 2 (Figura 12). Quando os relés 1 e 2 estão ligados e os relés 3 e 4 desligados, a polaridade é invertida, ou seja, negativo na saída do relé 1 e positivo na saída do relé 2 (Figura 13). 


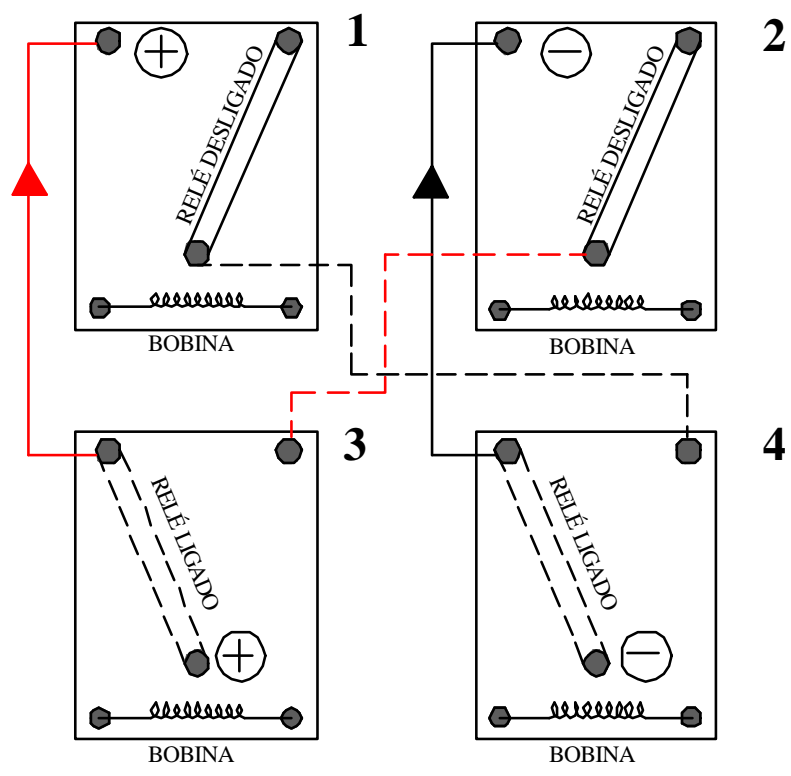

Figura 12 - Polarização direta.

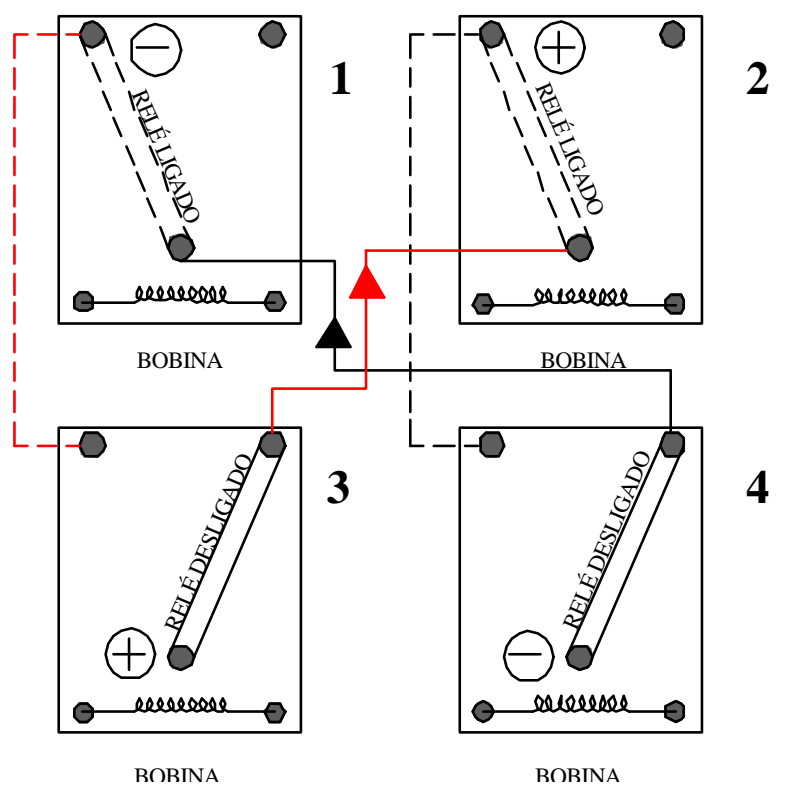

Figura 13 - Polarização invertida

\subsubsection{Movimentação dos carrinhos}

Um componente importante para que a movimentação do carrinho possa ser controlada via computador é o interruptor magnético (Red switch). Este serve para 
indicar ao programa o momento em que o carrinho deve inverter o sentido de caminhamento.

No carrinho foram colocados ímãs, quando o ímã se aproxima do interruptor magnético, este fecha um contator mecânico encapsulado sob vácuo e envia um sinal para o computador. Este sinal é lido pelo computador através da porta paralela nos endereços 379 e 37A. Os interruptores estão fixados em estacas no início e no final de cada canteiro (Figura 14).

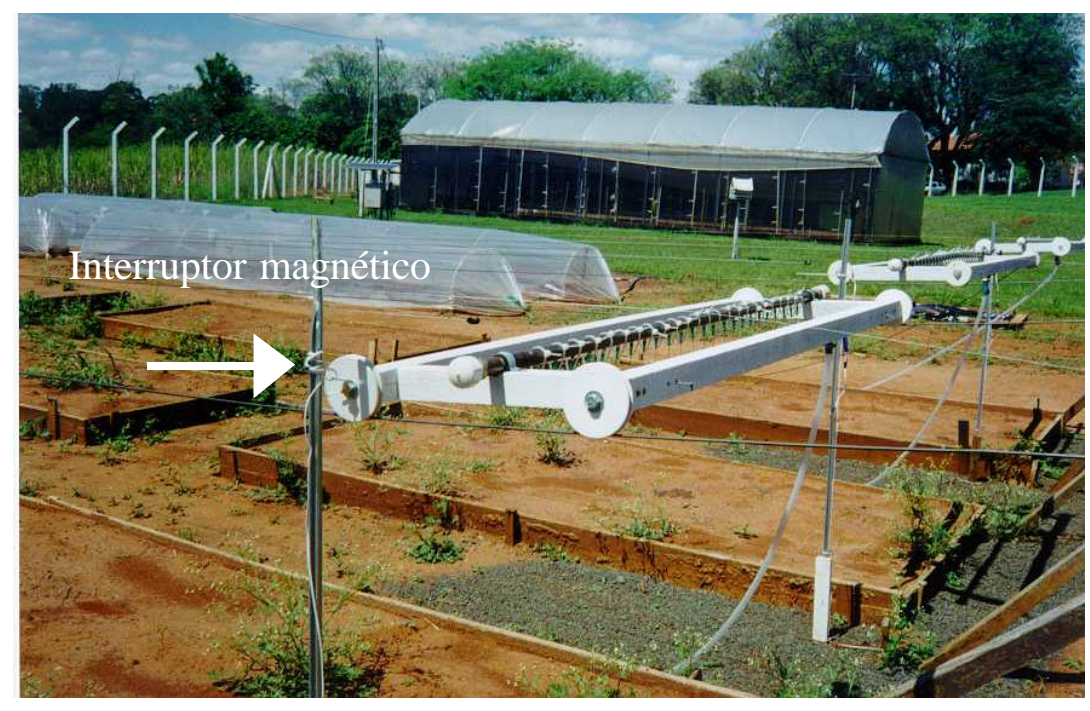

Figura 14 - Interruptor magnético instalado na extremidade do canteiro.

Os bits de leitura normalmente estão em nível alto (5v). Quando o ímã se aproxima do interruptor magnético, provoca uma ligação ao terra do sistema no bit, que passa a ser nível baixo (0v).

\subsubsection{Programa para controle da irrigação}

O Delphi é um ambiente de programação baseado na linguagem Pascal padrão. Esse ambiente implementa alguns comandos novos, notadamente na parte de criação de Classes e Objetos. Por causa desses comandos adicionais, o Pascal do Delphi é conhecido como Object Pascal. 
A função do programa é ligar o sistema, realizar o número de passadas irrigando e injetando fertilizante quando necessário, e desligar o sistema.

O Delphi não possui em seu conjunto de componentes nenhum que possibilite acessar a porta paralela (a saída da impressora). É necessário utilizar um componente à parte, o IOport (Braga, 1999), que deverá ser instalado no ambiente Delphi. Um componente é um conjunto de arquivos contendo definições, códigos e recursos, de forma a instruir o Windows a manipular convenientemente eventos e propriedades agrupadas em torno de uma estrutura concisa.

Cada canteiro possui um programa que controla suas atividades. O aplicativo desenvolvido no Delphi comanda a abertura e o fechamento das válvulas e o acionamento do motor.

Na página inicial, estão os dados preliminares da Dissertação (título, autor e orientador) (Figura 15).

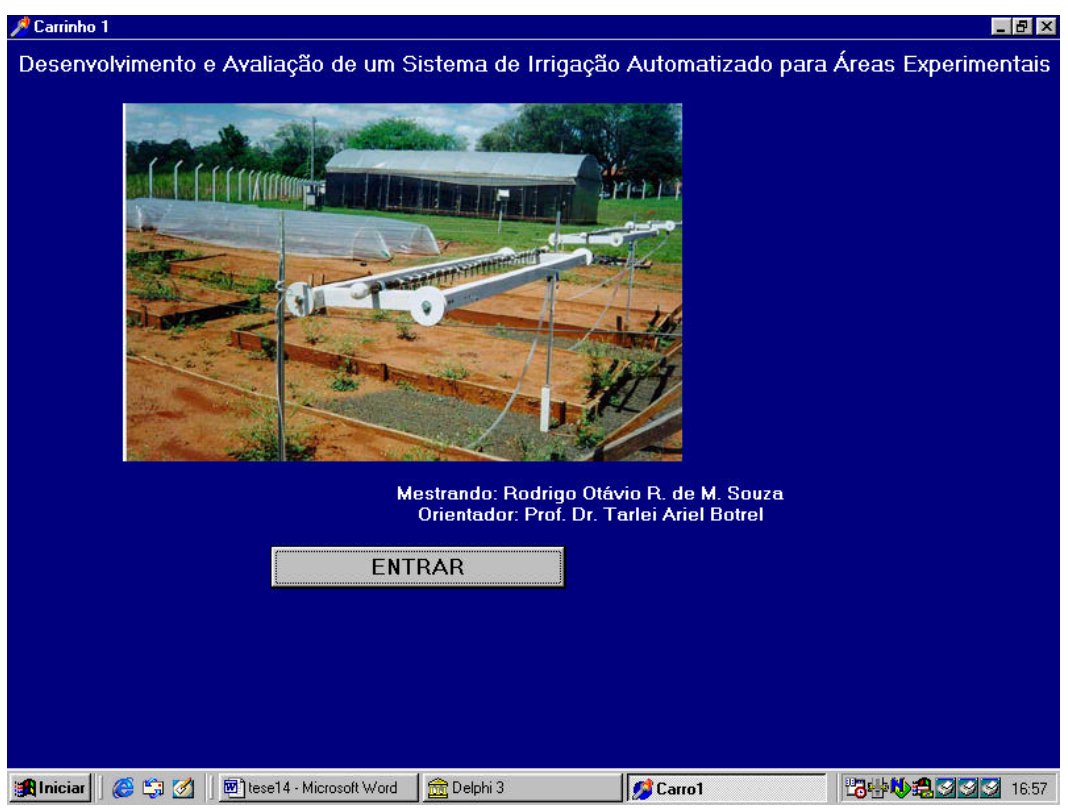

Figura 15 - Página inicial do programa.

No programa, o usuário tem a possibilidade de planejar o início da irrigação nos três períodos do dia (manhã, tarde e noite). Além de indicar o início da irrigação, o usuário informa o número de passadas em que o sistema aplica água e o número de 
passadas em que o sistema aplica água com fertilizante (Figura 16). O programa também fornece informações sobre as últimas irrigações (Figura 17).

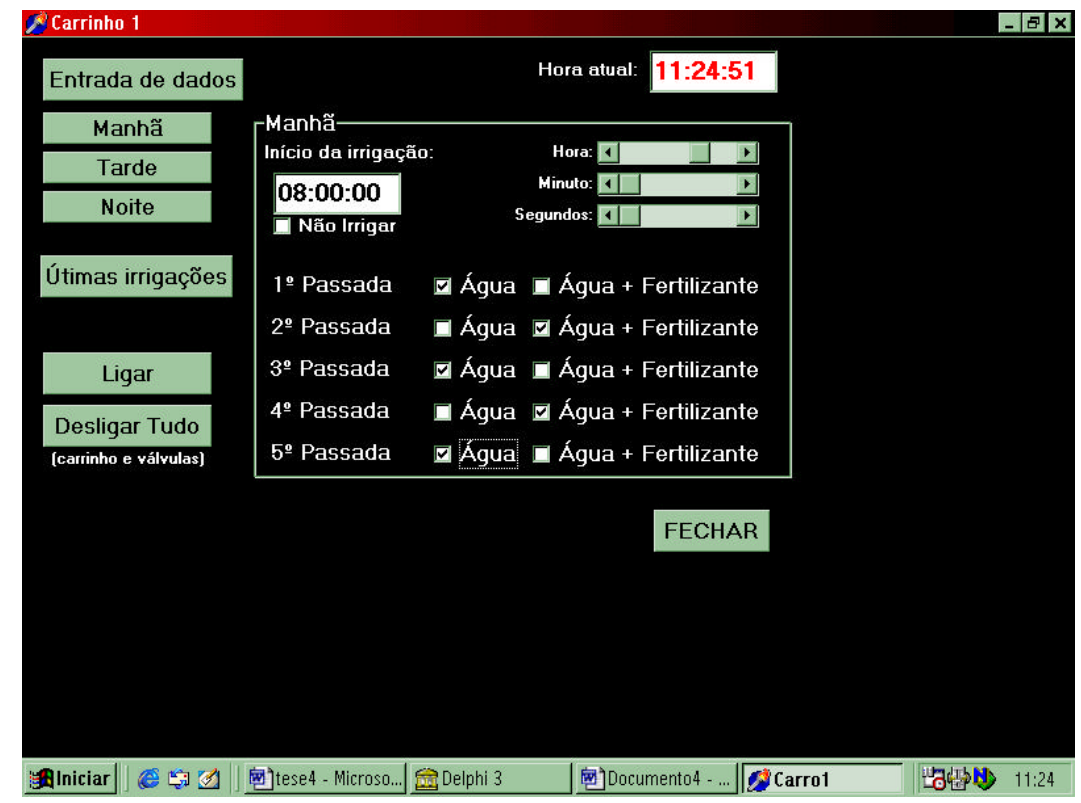

Figura 16 - Entrada de dados para manejo da irrigação.

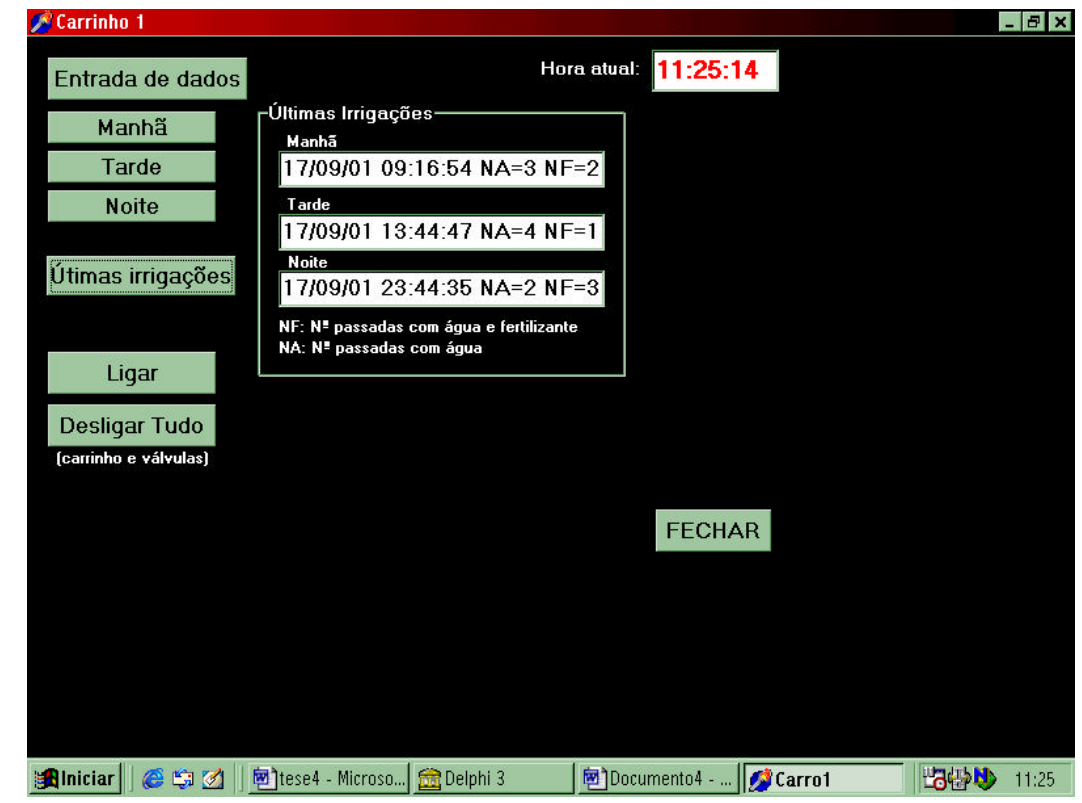

Figura 17 - Informações sobre as últimas irrigações. 
A Figura 18 apresenta o fluxograma utilizado no desenvolvimento do programa. A programação completa, na linguagem Object Pascal, está em anexo.

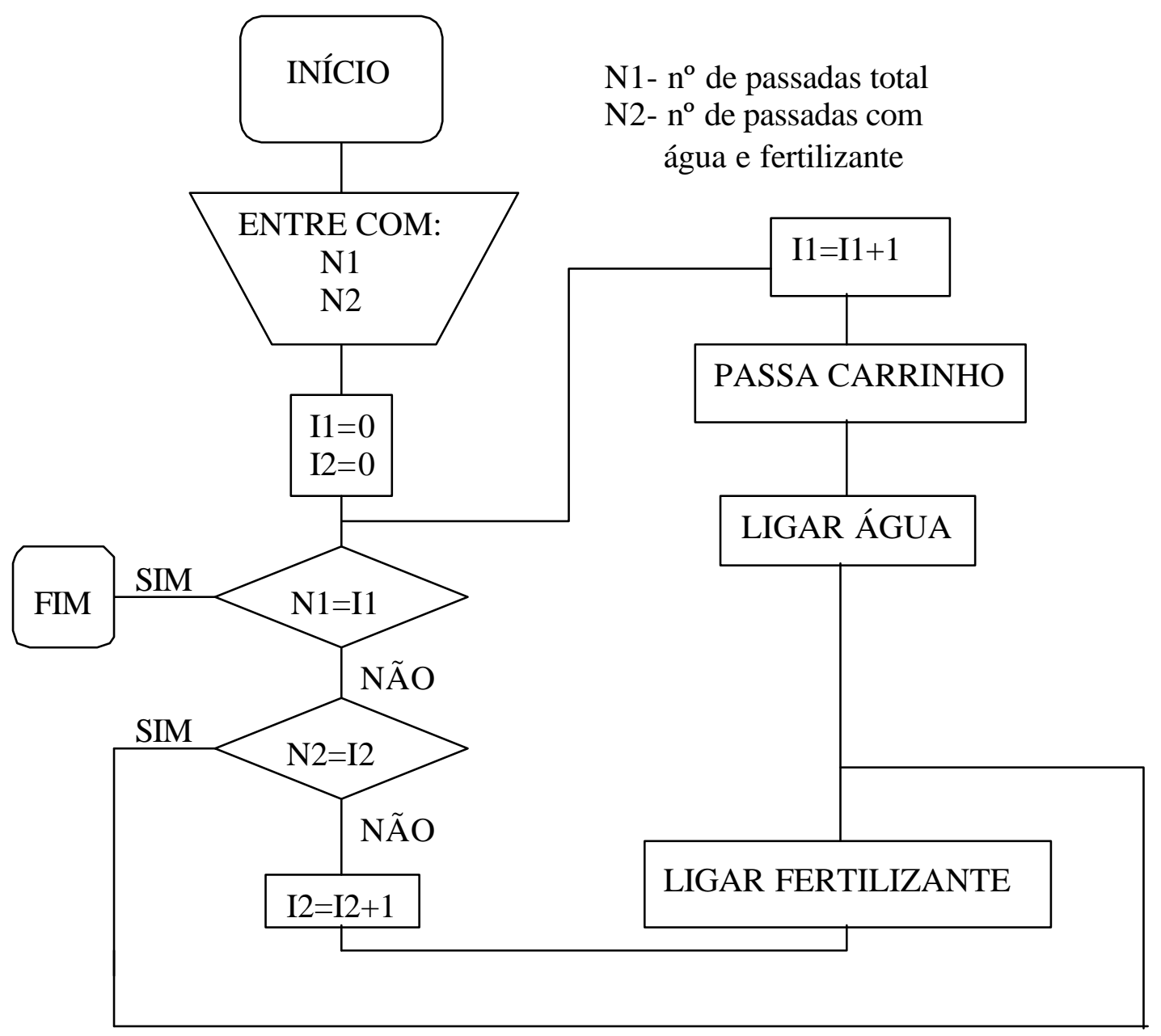

Figura 18 - Fluxograma utilizado no desenvolvimento do programa.

\subsection{Avaliação do sistema}

\subsubsection{Uniformidade de distribuição de água}

O sistema de irrigação foi ensaiado com uma pressão de serviço de 50kPa. Em cada canteiro, o equipamento realizou dez passadas sobre uma malha de coletores. Foi 
mensurado o volume precipitado em cada coletor. Posteriormente, calculou-se a lâmina média aplicada.

A lâmina média aplicada em cada canteiro foi de $6,12 \mathrm{~mm}, 6,47 \mathrm{~mm}$ e $6,60 \mathrm{~mm}$, respectivamente, para os canteiros I, II e III.

Os valores médios de lâmina aplicada em cada setor dos canteiros podem ser vistos na Tabela 7.

Tabela 7. Lâmina média aplicada em cada setor.

\begin{tabular}{cccccc}
\hline & \multicolumn{5}{c}{ Lâmina $(\mathrm{mm})$} \\
\hline Canteiro I & 6,2 & S2 & S3 & S4 & Média \\
\hline Canteiro II & 6,4 & 6,3 & 6,3 & 5,8 & 6,1 \\
Canteiro III & 6,6 & 6,7 & 6,5 & 6,6 & 6,5 \\
\hline
\end{tabular}

Os diferentes valores de lâmina média aplicada se devem principalmente à variação da velocidade periférica do motor, responsável pela movimentação do sistema. O motor do canteiro I apresentou uma rotação de 28,9 rpm; o motor do canteiro II, uma rotação de 24,9rpm; e o motor do canteiro III, 26,1rpm.

Os motores utilizados nesses equipamentos apresentam apenas duas velocidades, portanto, o valor da lâmina a ser aplicada deve ser controlada pelo número de passadas do sistema. Neste caso, para que se aplique a lâmina necessária com certa precisão, deve-se aplicar uma lâmina pequena por passada, lembrando que o tempo total entra duas passadas não deve ser muito longo para evitar a evaporação. No presente caso, o sistema aplicou uma lâmina média de $0,64 \mathrm{~mm}$ por passada, sendo que o tempo médio de cada passada foi de $6,7 \mathrm{~min}$.

Para uma maior otimização da mão-de-obra e do uso do sistema, recomenda-se que equipamento aplique a lâmina necessária em apenas uma passada. Para que isto ocorra, o sistema deve possuir um dispositivo que permita a regulagem da velocidade de caminhamento do equipamento, conforme a lâmina necessária. 
Caso o objetivo seja controlar a lâmina aplicada através da velocidade periférica do motor, recomenda-se a utilização de motores que se enquadrem dentro dos limites necessários de variação de velocidade.

Os três sistemas desenvolvidos apresentaram boa uniformidade de distribuição de água, segundo classificação sugerida pela ABNT (1998). Os coeficientes de uniformidades apresentados (CUC) foram 86,3\%; 88,0\% e 87,7\%; respectivamente, para os canteiros I, II e III.

Uma variável que influencia a uniformidade de distribuição de água é a altura de caminhamento do carrinho. Se o sistema estiver muito próximo à superfície do solo, não haverá uma fragmentação do jato de água, concentrando a precipitação em determinadas áreas. Por outro lado, se o sistema estiver muito distante da superfície do solo, estará mais suscetível à influência do vento.

Para uma maior uniformidade, recomenda-se que o sistema aplique água a uma mesma altura ao longo de todo o canteiro. $\mathrm{Na}$ escolha da altura de caminhamento do sistema, devem ser considerados os aspectos comentados no parágrafo anterior, além das características da cultura a ser implantada.

\subsubsection{Vazão das agulhas}

Foram calculadas as vazões individuais de sessenta agulhas, a partir da mensuração do volume de água precipitado durante o tempo de um minuto. Com estes valores, foram calculados o coeficiente de variação de fabricação e o valor médio de vazão.

O coeficiente de variação de fabricação das agulhas foi de 2,17\%, valor considerado bom segundo a ABNT (1986) e excelente para Solomon (1979). O valor médio de vazão das agulhas foi de $4,64 \mathrm{~L} \mathrm{~h}^{-1}$.

Existem diversos modelos de agulhas no mercado. Essa deve ser escolhida conforme as necessidades de projeto. Antes de adotar um determinado modelo, recomenda-se ter os dados referentes à vazão média, coeficiente de variação de 
fabricação e a relação vazão versus pressão. Essa verificação é importante, pois informa se o sistema funcionará nas condições preestabelecidas.

\subsubsection{Relação vazão versus pressão}

Para expressar a relação vazão versus pressão do emissor, foram coletadas simultaneamente as vazões das vinte e quatro agulhas de cada carrinho. O tempo de coleta foi de um minuto, sendo três repetições para cada carrinho. Na Tabela 8, pode-se observar a soma total da vazão das agulhas nas pressões de 20,30, 40, 50 e 60kPa para os três carrinhos.

Tabela 8. Soma total das vazões das agulhas em diversas pressões.

\begin{tabular}{ccccc}
\hline Pressão & $\begin{array}{c}\text { Carrinho I } \\
\text { Vazão }\left(\mathrm{L} \mathrm{h}^{-1}\right)\end{array}$ & $\begin{array}{c}\text { Carrinho II } \\
\text { Vazão }\left(\mathrm{L} \mathrm{h}^{-1}\right)\end{array}$ & $\begin{array}{c}\text { Carrinho III } \\
\text { Vazão }\left(\mathrm{L} \mathrm{h}^{-1}\right)\end{array}$ & Média $\left(\mathrm{L} \mathrm{h}^{-1}\right)$ \\
\hline $20 \mathrm{kpa}$ & 55,8 & 56,4 & 49,2 & 53,8 \\
$30 \mathrm{kPa}$ & 74,4 & 82,8 & 73,8 & 77,0 \\
$40 \mathrm{kPa}$ & 93,0 & 95,4 & 94,2 & 94,2 \\
$50 \mathrm{kPa}$ & 114,6 & 113,4 & 112,2 & 113,4 \\
$60 \mathrm{kPa}$ & 124,8 & 125,4 & 126,0 & 125,4 \\
\hline
\end{tabular}

A relação vazão versus pressão das agulhas foi obtida pelo ajuste da equação potencial com pares de valores médios de vazão e pressão.

Por análise de regressão foi obtida a seguinte expressão:

$$
q=5,3834 \cdot H^{0,7749}
$$

em que:

q - vazão das agulhas $\left(\mathrm{L} \mathrm{h}^{-1}\right)$;

$\mathrm{H}$ - pressão na entrada do emissor $(\mathrm{kPa})$.

O coeficiente de determinação $\mathrm{r}^{2}$ foi 0,9959 . A Figura 19 mostra o gráfico da equação acima. 


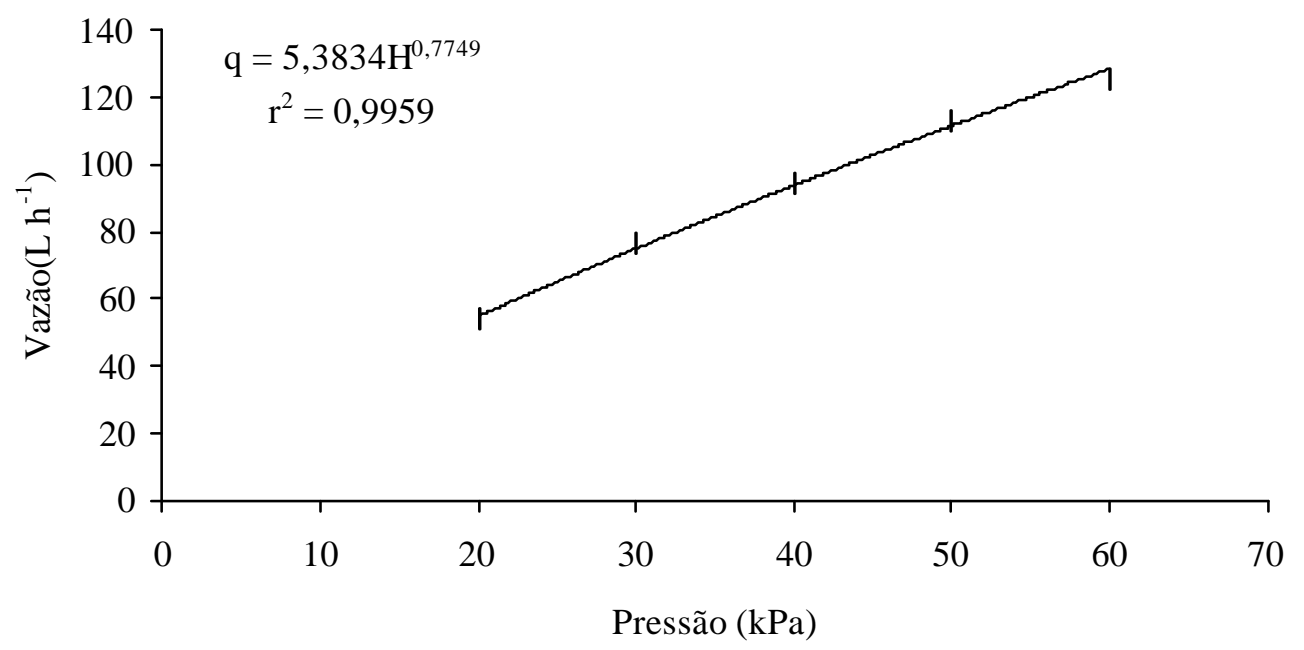

Figura 19 - Gráfico representativo da relação vazão versus pressão das agulhas.

Moraes (2001) realizou ensaios para obtenção da relação vazão versus pressão de outros tipos de agulhas: a) Preta (25x7), diâmetro de $0,7 \mathrm{~mm}$ e comprimento de $25 \mathrm{~mm}$; b) Rosa $(20 x 5,5)$, diâmetro de $0,55 \mathrm{~mm}$ e comprimento de $20 \mathrm{~mm}$. As equações a seguir representam a vazão individual da agulha em função da pressão na entrada do tubo:

$$
\begin{aligned}
& \text { Preta: } \mathrm{q}\left(\mathrm{L} \mathrm{h}^{-1}\right)=0,186 \cdot \mathrm{H}(\mathrm{kPa})^{0,669} \\
& \text { Rosa: } \mathrm{q}\left(\mathrm{L} \mathrm{h}^{-1}\right)=0,074 \cdot \mathrm{H}(\mathrm{kPa})^{0,632}
\end{aligned}
$$

A presente agulha possui um regime de escoamento instável de acordo com o valor do expoente ' $x$ ' da equação potencial. Este valor de $x=0,77$, próximo de 1 , expressa o quanto a vazão do emissor é sensível à variação de pressão. Isso ocorre porque as agulhas não possuem nenhum mecanismo de compensação, pois não são equipamentos de uso específico desta atividade.

\subsection{Lista de material com tabela de preços}

A seguir, apresenta-se uma listagem contendo a especificação de todos os componentes utilizados no experimento. Esta listagem está dividida em duas partes: 
estrutural e eletrônica (automação). Os preços desses componentes foram cotados no comércio de Piracicaba.

$\mathrm{O}$ valor total gasto no projeto foi de $\mathrm{R} \$ 733,57$. A parte estrutural do projeto custou $\mathrm{R} \$ 583,07$ e a automação $\mathrm{R} \$ 150,50$. O motor de $12 \mathrm{vcc}$ representou 56,6\% do valor gasto em estrutura e a fiação do sistema, $28,6 \%$ do valor gasto na automação.

Tabela 9. Lista de material e preços da parte estrutural do sistema de irrigação: PU-preço unitário e PT-preço total.

\begin{tabular}{cccc}
\hline Material & Quantidade & PU (R\$) & PT (R\$) \\
\hline Tubo cobre (22mm) & $4,4 \mathrm{~m}$ & 3,20 & 14,08 \\
Luva PVC 20mm & 3 un & 0,40 & 1,20 \\
Cap PVC 20mm & 3 un & 0,17 & 0,51 \\
Registro globo 16mm & 3 un & 5,00 & 15,00 \\
Arame de aço & $93 \mathrm{~m}$ & 0,10 & 9,30 \\
Estrutura de madeira & 3 un & 14,00 & 42,00 \\
Rodas & 16 un & 1,50 & 24,00 \\
Agulhas (25x8) & 72 un & 0,06 & 4,32 \\
Parafusos, pregos e acessórios & 1 un & 5,00 & 5,00 \\
Motor 12vcc & 3 un & 110,00 & 330,00 \\
Polia & 3 un & 3,00 & 9,00 \\
Cabo de aço & $100 \mathrm{~m}$ & 0,35 & 35,00 \\
Mola & 3 un & 1,67 & 5,01 \\
Bateria 12v & $25 \mathrm{~m}$ & 0,75 & 18,75 \\
Braçadeira & 3 un & 0,80 & 2,40 \\
Mangueira 16mm (transparente) & 6 un & 0,50 & 3,00 \\
Te plástico p/mangeira 16mm & 1 un & 60,00 & 6,50 \\
Conector plástico 16mm & 15 un & 0,30 &
\end{tabular}


Tabela 10. Lista de material e preços da parte eletrônica referente à automação do sistema de irrigação: PU-preço unitário e PT-preço total.

\begin{tabular}{cccc}
\hline Produtos & Quantidade & PU (R\$) & PT (R\$) \\
\hline Transistor (BC 548) & 11 un & 0,20 & 2,20 \\
Relé 12v & 17 un & 1,90 & 32,30 \\
Resitor & 22 un & 0,05 & 1,10 \\
Isolador óptico (Til 111) & 11 un & 1,70 & 18,70 \\
Placa de montagem & 6 un & 2,00 & 12,00 \\
Diodo (1N4007) & 11 un & 0,10 & 1,10 \\
Solda & 1 un & 1,50 & 1,50 \\
Conector DB25 & 2 un & 0,90 & 1,80 \\
Fio (0,14mm) & $100 \mathrm{~m}$ & 0,15 & 15,00 \\
Fio polarizado(1mm) & $80 \mathrm{~m}$ & 0,35 & 28,00 \\
Caixa de madeira & 1 un & 10,00 & 10,00 \\
Interruptor magnético & 6 un & 0,80 & 4,80 \\
Cabo manga & $1,5 \mathrm{~m}$ & 5,00 & 7,50 \\
Válvula & 5 un & 2,70 & 13,50 \\
Terminal de fio & 20 un & 0,05 & 1,00 \\
\hline
\end{tabular}

\subsection{Considerações gerais}

As pesquisas que testam novos equipamentos visam obter alternativas para substituição de produtos existentes comercialmente no mercado. Para comprovar a viabilidade desse novo equipamento, devem ser realizados testes de viabilidade técnica e viabilidade econômica.

As agulhas testadas neste experimento apresentaram bom desempenho técnico e baixo custo de aquisição (R \$ 6,00/100un). Entretanto, apresentam uma desvantagem em relação aos emissores disponíveis no mercado: as agulhas são equipamentos pontiagudos que exigem um maior cuidado durante o manuseio e instalação. Portanto, recomenda-se o uso de agulhas em áreas experimentais de pequeno porte, facilitando seu manejo. 
Para obter uma melhor caracterização do equipamento, deve-se fornecer informações sobre as sua limitações. No caso desse equipamento de movimentação linear cabe, em estudos futuros, realizar testes que indiquem qual a real capacidade do sistema. Em função do peso do carrinho, peso da mangueira e potência do motor, obter o comprimento máximo do canteiro e a largura máxima do carrinho. Assim, o sistema estará irrigando o máximo de área que a capacidade do equipamento permite.

Para que possa ser verificada a durabilidade dos componentes, devem ser feitos novos acompanhamentos do desempenho do sistema, observando seu funcionamento ao longo do ciclo de uma determinada cultura. 


\section{CONCLUSÕES}

Com base nos resultados obtidos e nas condições em que foram realizados os ensaios de laboratório e experimento de campo, chegourse às seguintes conclusões:

a) O sistema de irrigação proposto foi desenvolvido e avaliado. Executou todas as suas funções corretamente, obedecendo a comandos enviados via computador;

b) O programa desenvolvido no ambiente Delphi, além de comandar com precisão um sistema de irrigação, possui outras vantagens: pode ser utilizado em computadores obsoletos, e apresentam facilidade de programação e personalização, o que atende ao interesse específico de cada situação de projeto;

c) A avaliação mostrou que o sistema apresentou boa uniformidade de distribuição de água e bom coeficiente de variação de fabricação dos emissores (agulhas), de acordo com as normas da ABNT. Por análise de regressão, foi obtida a seguinte expressão, que representa a relação vazão versus pressão das agulhas: q $\left(\mathrm{L} \mathrm{h}^{-1}\right)$ $=5,3834 \cdot \mathrm{H}(\mathrm{kPa})^{0,7749}$. 
ANEXOS 
unit carro;

interface

uses

Windows, Messages, SysUtils, Classes, Graphics, Controls, Forms, Dialogs,

StdCtrls, IOport, ExtCtrls, math;

private

\{Private declarations \}

function

carrinho1(bits:string):string;

function s3(bit:string):string;

function s4(bit:string):string;

public

\{Public declarations \}

end;

var

Form1: TForm1;

j,i,c, agua, fert, pa, sa,ta,qa,quia, pf,sf,tf,qf,quif,na,nf:integer;

bits, bit, ler, lert, lern, h,m, segu, ht,mt, segut, hn,mn, segun:string;

horadata, horadatat, horadatan:textfile;

horaatual:ttime;

implementation

$\{\$ \mathrm{R} * . \mathrm{DFM}\}$

function IntToBin(Value: LongInt;Size:

Integer): String;
\{CONVERTE UMA STRING EM BINÁRIO\}

var

i: Integer;

begin

Result:=";

for $\mathrm{i}:=$ Size downto 0 do

begin

if Value and $(1$ shl i $)<>0$

then

begin

Result:=Result+'1';

end

else

begin

Result:=Result+'0';

end;

end;

end;

function BinToInt(Value: String): extended;

\{CONVERTE UM NUMERO BINÁRIO EM INTEIRO\}

var

i,Size: Integer;

begin

Result :=0; Size $:=$ Length(Value);

for $\mathrm{i}$ :=size downto 1 do

begin

if Copy(Value,i,1)='1' then

begin

Result := Result+(1*power(2,size-i)); 
end;

end;

end;

\{SELECIONAR BITS DA PORTA 378\}

function

tform1.carrinho1(bits:string):string;

var

dec:integer;

dec1:string;

bin, hex, bin1,

n1,n2,n3,n4,n5,n6,n7,n8:string;

begin

ioport1.portaddress: $=\$ 378 ; \quad$ ioport1.read;

dec:=ioport1.portdata;

bin:=IntToBin(dec,8);

$\mathrm{n} 1:=\operatorname{copy}(\operatorname{bin}, 9,1) ; \quad \mathrm{n} 2:=\operatorname{copy}(\operatorname{bin}, 8,1)$;

n3:=copy (bin, 7,1); $\quad$ n4:=copy (bin, 6,1);

n5:=copy(bin,5,1); n6:=copy (bin, 4,1$)$;

n7:=copy(bin,3,1); n8:=copy(bin,2,1);

bin1:=n8+n7+n6+n5+bits;

$\operatorname{dec} 1:=$ floattostr(bintoint(bin1));

hex:='\$'+(inttohex(strtoint(dec1),2));

ioport1.portaddress: $=\$ 378$;

ioport1.portdata:=strtoint(hex);

ioport1.write;

end;

\{LER PINO S3 DA PORTA 379\}

function tform1.s3(bit:string):string;

var

dec:integer;

bin,n:string; begin

ioport1.portaddress: $=\$ 379 ; \quad$ ioport1.read;

dec:=ioport1.portdata;

bin:=IntToBin $(\operatorname{dec}, 8) ; \quad n:=\operatorname{copy}($ bin, 6,1$)$;

result: $=\mathrm{n}$;

end;

\{LER PINO S4 DA PORTA 379\}

function tform1.s4(bit:string):string;

var

dec:integer;

bin,n:string;

begin

ioport1.portaddress: $=\$ 379 ; \quad$ ioport1.read;

dec:=ioport1.portdata;

bin:=IntToBin $(\operatorname{dec}, 8) ; \quad \mathrm{n}:=\operatorname{copy}(\operatorname{bin}, 5,1)$;

result:=n;

end;

procedure

TForm1.Timer1Timer(Sender: TObject);

var

horaatual:ttime;

hor, min, segundos :string;

h,m,seg,s:word;

begin

horaatual:=now;

decodetime(horaatual,h,m,seg,s);

hor:=formatfloat('\#0\#',h);

min:=formatfloat('\#0\#',m);

segundos:=formatfloat('\#0\#',seg);

edit1.text:=hor +':'+ min+':'+ segundos; 


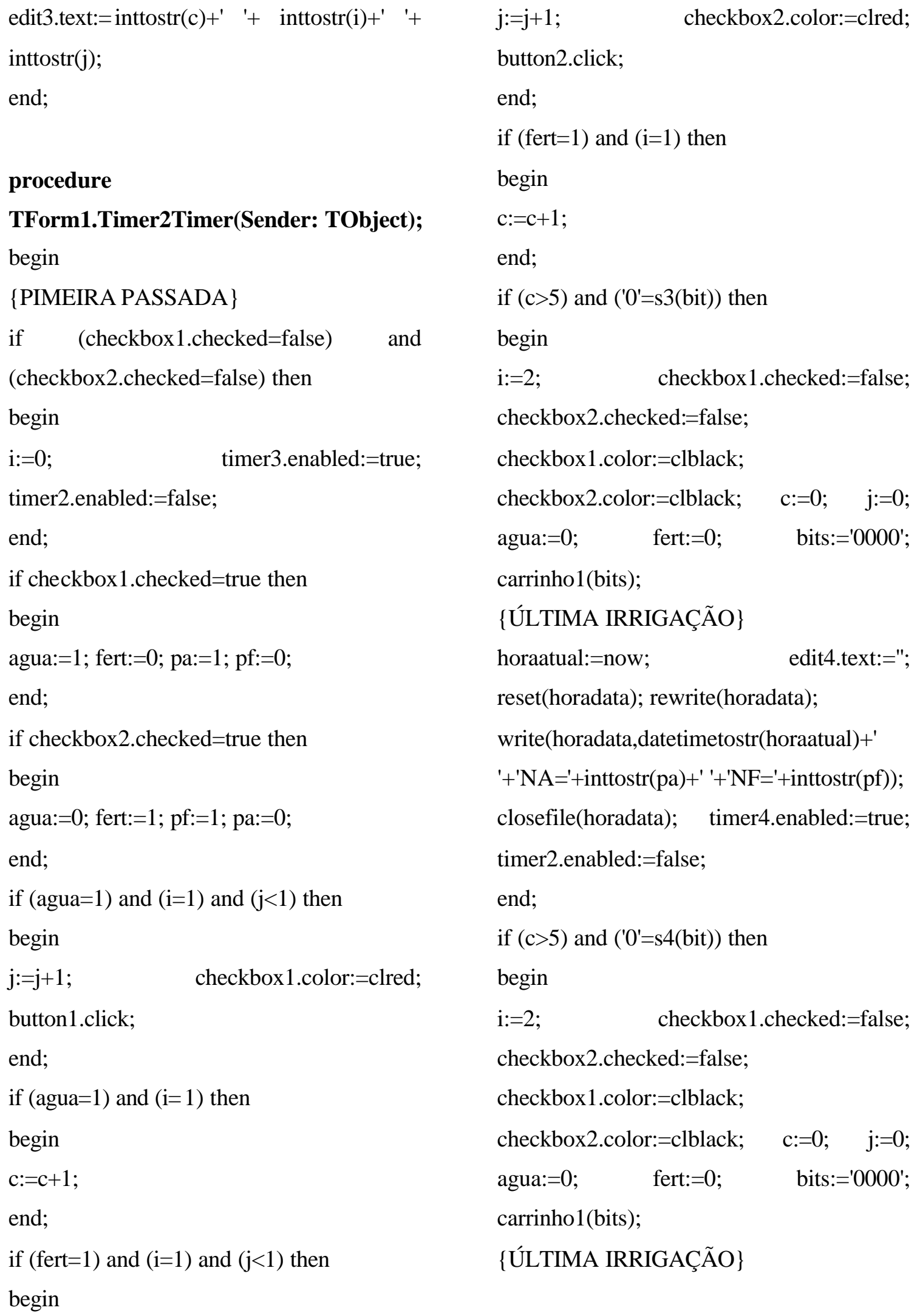




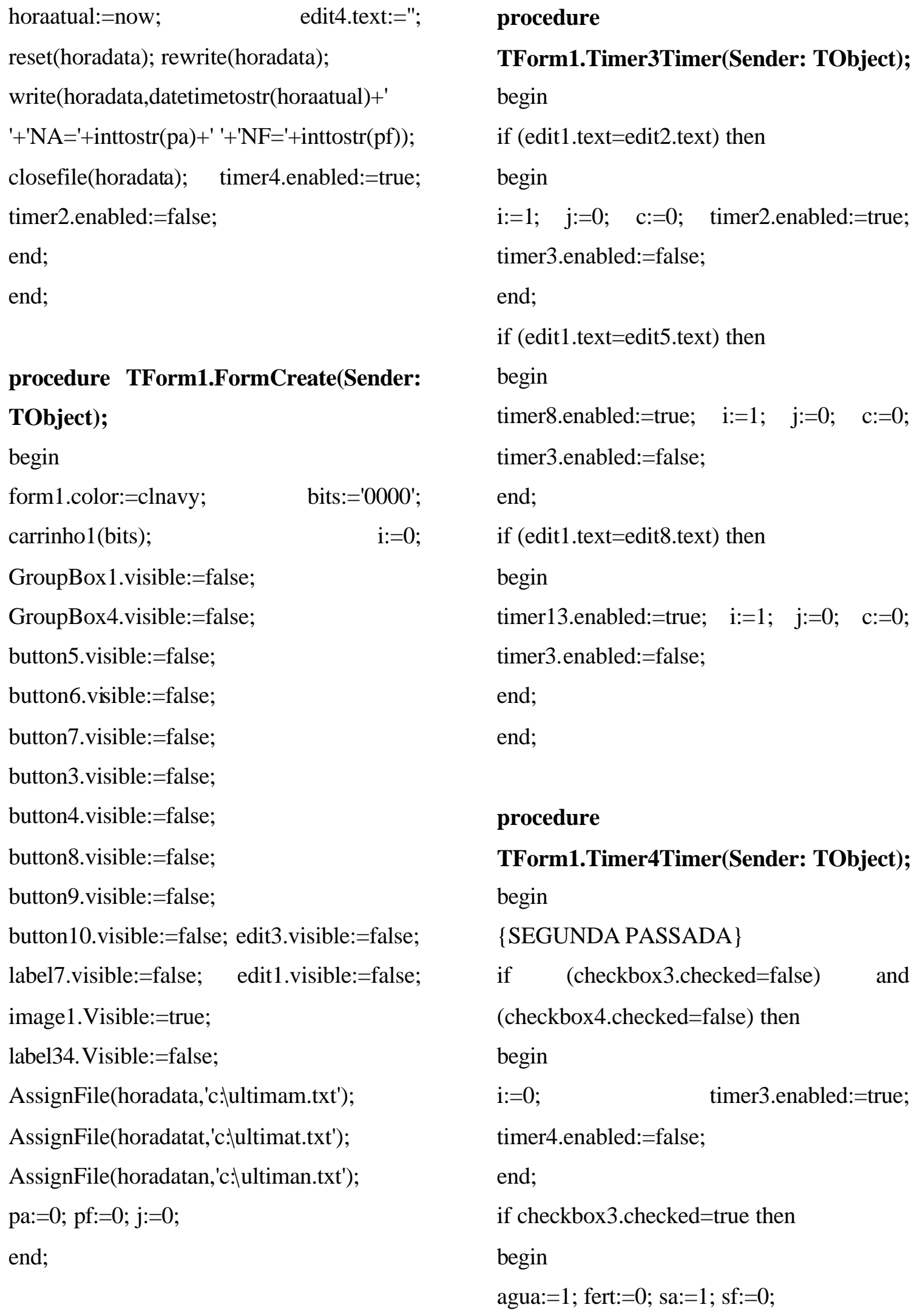


end;

if checkbox4.checked=true then

begin

agua: $=0$; fert:=1; sf:=1; sa:=0;

end;

if (agua=1) and $(\mathrm{i}=2)$ and $(\mathrm{j}<1)$ then

begin

$\mathrm{j}:=\mathrm{j}+1 ; \quad \quad$ checkbox3.color:=clred;

button1.click;

end;

if (agua $=1)$ and $(\mathrm{i}=2)$ then

begin

$\mathrm{c}:=\mathrm{c}+1$;

end;

if (fert=1) and $(\mathrm{i}=2)$ and $(\mathrm{j}<1)$ then

begin

$\mathrm{j}:=\mathrm{j}+1 ; \quad$ checkbox4.color:=clred;

button2.click;

end;

if (fert=1) and ( $\mathrm{i}=2)$ then

begin

$\mathrm{c}:=\mathrm{c}+1$;

end;

if (c>5) and (' $\left.0^{\prime}=\mathrm{s} 3(\mathrm{bit})\right)$ then

begin

$\mathrm{i}:=3 ; \quad$ checkbox3.checked:=false;

checkbox4.checked:=false;

checkbox3.color:=clblack;

checkbox4.color:=clblack; $\quad \mathrm{c}:=0 ; \quad \mathrm{j}:=0$;

agua: $=0 ; \quad$ fert: $=0 ; \quad$ bits:='0000';

carrinho1(bits); na:=pa+sa; nf:=pf+sf;

\{ÚLTIMA IRRIGAÇÃO\} horaatual:=now; $\quad$ edit4.text:=";

reset(horadata); rewrite(horadata);

write(horadata,datetimetostr(horaatual)+'

'+'NA='+inttostr(na)+' '+'NF='+inttostr(nf));

closefile(horadata); timer4.enabled:=false;

timer5.enabled:=true;

end;

if (c>5) and (' $\left.0{ }^{\prime}=\mathrm{s} 4(\mathrm{bit})\right)$ then

begin

$\mathrm{i}:=3 ; \quad$ checkbox3.checked:=false;

checkbox4.checked:=false;

checkbox3.color:=clblack;

checkbox4.color: $=$ clblack; $\quad \mathrm{c}:=0 ; \quad \mathrm{j}:=0$;

agua: $=0 ; \quad$ fert: $=0 ; \quad$ bits:='0000';

carrinho1(bits); na:=sa+pa; nf:=sf+pf;

\{ÚLTIMA IRRIGAÇÃO\}

horaatual:=now; edit4.text:=";

reset(horadata); rewrite(horadata);

write(horadata,datetimetostr(horaatual)+'

'+'NA='+inttostr(na)+' '+'NF='+inttostr(nf));

closefile(horadata); timer4.enabled:=false;

timer5.enabled:=true;

end;

end;

procedure

TForm1.Button1Click(Sender: TObject);

begin

if ' 0 ' $=\mathrm{s} 3$ (bits) then

begin

bits:='0101'; carrinho1(bits);

end;

if ' 0 ' $=\mathrm{s} 4$ (bits) then 


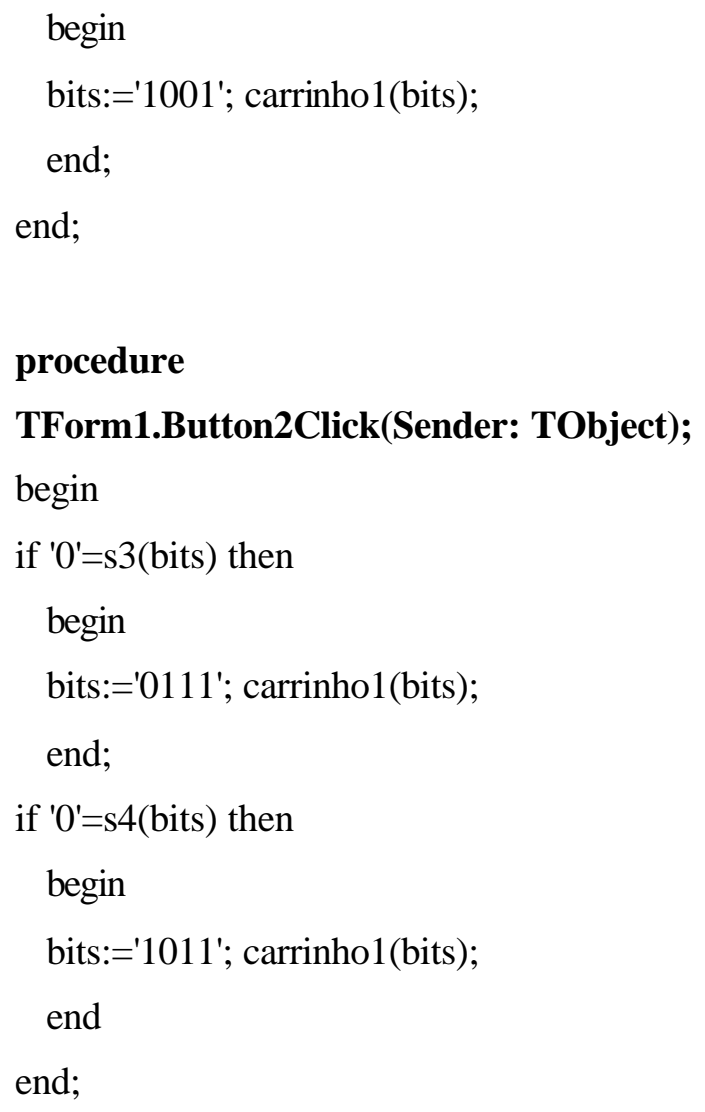

begin

agua: $=0$; fert: $=1 ; \mathrm{tf}:=1 ;$ ta: $=0$;

end;

if (agua=1) and $(\mathrm{i}=3)$ and $(\mathrm{j}<1)$ then

begin

$\mathrm{j}:=\mathrm{j}+1 ; \quad \quad$ checkbox 5 .color:=clred;

button1.click;

end;

if (agua $=1)$ and $(i=3)$ then

begin

$\mathrm{c}:=\mathrm{c}+1$;

end;

if (fert=1) and $(\mathrm{i}=3)$ and $(\mathrm{j}<1)$ then

begin

$\mathrm{j}:=\mathrm{j}+1 ; \quad$ checkbox6.color:=clred;

button2.click;

end;

if (fert=1) and (i=3) then

begin

$\mathrm{c}:=\mathrm{c}+1$;

end;

if (c>5) and (' $0{ }^{\prime}=\mathrm{s} 3($ bit $\left.)\right)$ then

begin

$\mathrm{i}:=4 ; \quad$ checkbox5.checked:=false;

checkbox6.checked:=false;

checkbox5.color:=clblack;

checkbox6.color: $=$ clblack; $\quad \mathrm{c}:=0 ; \quad \mathrm{j}:=0$;

agua: $=0 ; \quad$ fert: $=0 ; \quad$ bits:='0000';

carrinhol(bits); na:=sa+pa+ta; nf:=sf+pf+tf;

\{ÚLTIMA IRRIGAÇÃO\}

horaatual:=now; $\quad$ edit4.text:=";

reset(horadata); rewrite(horadata); 
write(horadata,datetimetostr(horaatual)+'

'+'NA='+inttostr(na)+' '+'NF='+inttostr(nf));

closefile(horadata); timer5.enabled:=false;

timer6.enabled:=true;

end;

if (c>5) and (' $0{ }^{\prime}=\mathrm{s} 4($ bit $\left.)\right)$ then

begin

$\mathrm{i}:=4 ; \quad$ checkbox5.checked:=false;

checkbox6.checked:=false;

checkbox 5.color:=clblack;

checkbox6.color:=clblack; $\quad \mathrm{c}:=0 ; \quad \mathrm{j}:=0$;

agua: $=0 ; \quad$ fert: $=0 ; \quad$ bits:='0000';

carrinho1(bits); na:=sa+pa+ta; nf:=sf+pf+tf;

\{ÚLTIMA IRRIGAÇÃO\}

horaatual:=now; $\quad$ edit4.text:=";

reset(horadata); rewrite(horadata);

write(horadata,datetimetostr(horaatual)+'

'+'NA='+inttostr(na)+' '+'NF='+inttostr(nf));

closefile(horadata); timer5.enabled:=false;

timer6.enabled:=true;

end;

end;

procedure TForm1.Timer6Timer(Sender:

TObject);

begin

\{QUARTA PASSADA\}

if (checkbox7.checked=false) and

(checkbox8.checked=false) then

begin

$\mathrm{i}:=0 ; \quad$ timer3.enabled:=true;

timer6.enabled:=false;

end; if checkbox 7.checked=true then

begin

agua: $=1$; fert: $=0 ;$ qa: $=1 ;$ qf: $=0$;

end;

if checkbox8.checked=true then

begin

agua: $=0$; fert:=1; qf:=1; qa:=0;

end;

if (agua=1) and $(\mathrm{i}=4)$ and $(\mathrm{j}<1)$ then

begin

$\mathrm{j}:=\mathrm{j}+1 ; \quad \quad$ checkbox 7. color: $=$ clred;

button1.click;

end;

if (agua=1) and $(\mathrm{i}=4)$ then

begin

$\mathrm{c}:=\mathrm{c}+1$;

end;

if (fert=1) and $(\mathrm{i}=4)$ and $(\mathrm{j}<1)$ then

begin

$\mathrm{j}:=\mathrm{j}+1 ; \quad$ checkbox8.color:=clred;

button2.click;

end;

if (fert=1) and (i=4) then

begin

$\mathrm{c}:=\mathrm{c}+1$;

end;

if (c>5) and (' 0 '=s3(bit)) then

begin

$\mathrm{i}:=5 ; \quad$ checkbox7.checked:=false;

checkbox8.checked:=false;

checkbox7.color:=clblack;

checkbox8.color: $=$ clblack; $\quad \mathrm{c}:=0 ; \quad \mathrm{j}:=0$;

agua: $=0 ; \quad$ fert: $=0 ; \quad$ bits:='0000'; 


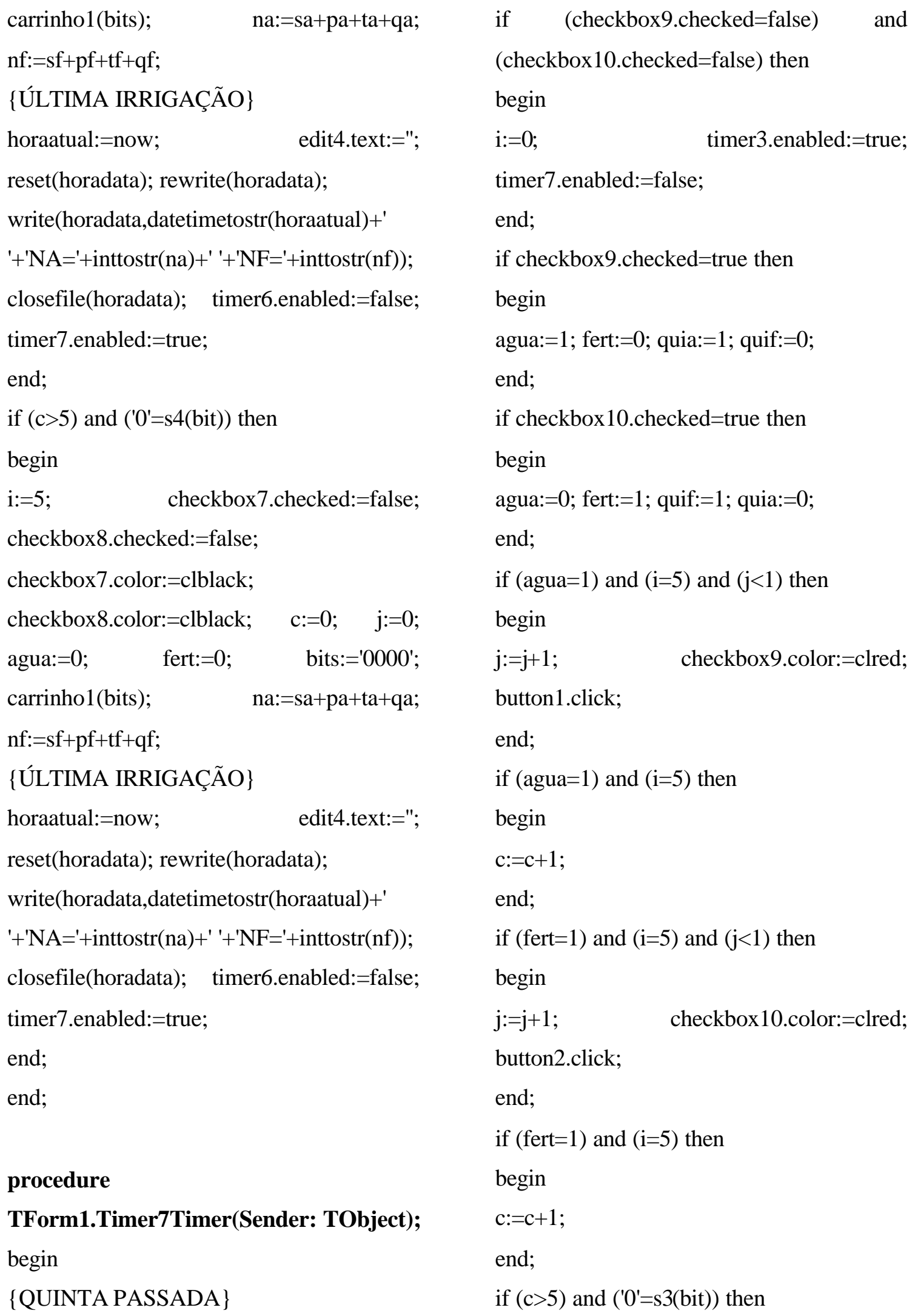


begin

$\mathrm{i}:=0$;

checkbox10.checked:=false;

checkbox9.color:=clblack;

checkbox10.color: $=$ clblack; $\quad \mathrm{c}:=0 ; \quad \mathrm{j}:=0$;

agua: $=0 ; \quad$ fert: $=0 ; \quad$ bits:='0000';

carrinho1(bits); na: $=$ sa+pa+ta+qa+quia;

$\mathrm{nf}:=\mathrm{sf}+\mathrm{pf}+\mathrm{tf}+\mathrm{qf}+$ quif;

\{ÚLTIMA IRRIGAÇÃO\}

horaatual:=now;

edit4.text:=";

reset(horadata); rewrite(horadata);

write(horadata,datetimetostr(horaatual)+'

'+'NA='+inttostr(na)+' '+'NF='+inttostr(nf));

closefile(horadata); timer7.enabled:=false;

timer3.enabled:=true;

end;

if (c>5) and (' $\left.0{ }^{\prime}=\mathrm{s} 4(\mathrm{bit})\right)$ then

begin

$\mathrm{i}:=0 ; \quad$ checkbox9.checked:=false;

checkbox10.checked:=false;

checkbox9.color:=clblack;

checkbox10.color: $=$ clblack; $\quad \mathrm{c}:=0 ; \quad \mathrm{j}:=0$;

agua: $=0 ; \quad$ fert: $=0 ; \quad$ bits:='0000';

carrinho1(bits); na:=sa+pa+ta+qa+quia;

$\mathrm{nf}:=\mathrm{sf}+\mathrm{pf}+\mathrm{tf}+\mathrm{qf}+$ quif;

\{ÚLTIMA IRRIGAÇÃO\}

horaatual:=now;

edit4.text:=";

reset(horadata); rewrite(horadata);

write(horadata,datetimetostr(horaatual)+'

'+'NA='+inttostr(quia)+'

'+'NF='+inttostr(quif));

closefile(horadata); timer7.enabled:=false;

timer3.enabled:=true; end;

end;

\section{procedure}

TForm1.Button3Click(Se nder: TObject);

begin

button5.Visible:=true;

button6.Visible:=true;

button7.Visible:=true;

end;

\section{procedure}

\section{TForm1.Button4Click(Sender: TObject);}

begin

if (groupbox4.visible=false) then

begin

groupbox4.visible:=true;

end

else

groupbox4.visible:=false;

groupbox1.visible:=false;

groupbox2.visible:=false;

groupbox3.visible:=false; $\quad$ reset(horadata);

read(horadata,ler); $\quad$ edit4.text:=ler;

reset(horadatat); $\quad \operatorname{read}($ horadatat,lert);

edit6.text:=lert; $\quad$ reset(horadatan);

read(horadatan,lern); edit7.text:=lern;

end;

\section{procedure}

TForm1.ScrollBar1Change(Sender:

TObject); 
begin

h:=formatfloat('\#0\#',scrollbar1.position);

edit2.text:=h+':'+m+':'+segu;

checkbox22.checked:=false;

end;

procedure

TForm1.ScrollBar2Change(Sender:

TObject);

begin

m:=formatfloat('\#0\#',scrollbar2.position);

edit2.text:=h+':'+m+':'+segu;

checkbox22.checked:=false;

end;

procedure

\section{TForm1.ScrollBar3Change(Sender:}

\section{TObject);}

begin

segu:=formatfloat('\#0\#',scrollbar3.position);

edit2.text:=h+':'+m+':'+segu;

checkbox22.checked:=false;

end;

procedure

TForm1.ScrollBar4Change(Sender:

\section{TObject);}

begin

ht:=formatfloat('\#0\#',scrollbar4.position);

edit5.text:=ht+':'+mt+':'+segut;

checkbox21.checked:=false;

end; procedure

\section{TForm1.ScrollBar5Change(Sender:}

TObject);

begin

$\mathrm{mt}:=$ formatfloat('\#0\#',scrollbar5.position);

edit5.text:=ht+':'+mt+':'+segut;

checkbox21.checked:=false;

end;

procedure

TForm1.ScrollBar6Change(Sender:

TObject);

begin

segut:=formatfloat('\#0\#',scrollbar6.position)

; $\quad$ edit5.text:=ht+':'+mt+':'+segut;

checkbox 21.checked:=false;

end;

procedure

TForm1.Button5Click(Sender: TObject);

begin

groupbox1.visible:=true;

groupbox2.visible:=false;

groupbox3.visible:=false;

groupbox4.visible:=false;

end;

procedure

TForm1.Button6Click(Sender: TObject);

begin

groupbox1.visible:=false;

groupbox2.visible:=true; 
groupbox3.visible:=false;

groupbox4.visible:=false;

end;

procedure

TForm1.Button7Click(Sender: TObject);

begin

groupbox1.visible:=false;

groupbox2.visible:=false;

groupbox3.visible:=true;

groupbox4.visible:=false;

end;

procedure

TForm1.Timer8Timer(Sender: TObject);

begin

\{PIMEIRA PASSADA tarde\}

if (checkbox11.checked=false) and

(checkbox12.checked=false) then

begin

$\mathrm{i}:=0 ; \quad$ timer3.enabled:=true;

timer8.enabled:=false;

end;

if checkbox11.checked=true then

begin

agua: $=1 ;$ fert: $=0 ;$ pa: $=1 ; \mathrm{pf}:=0$;

end;

if checkbox12.checked=true then

begin

agua: $=0$; fert: $=1 ;$ pf:=1; pa: $=0$;

end; if (agua=1) and $(i=1)$ and $(j<1)$ then

begin

$\mathrm{j}:=\mathrm{j}+1$;

checkbox11.color:=clred;

button1.click;

end;

if $($ agua=1) and $(\mathrm{i}=1)$ then

begin

$\mathrm{c}:=\mathrm{c}+1$;

end;

if (fert=1) and (i=1) and $(j<1)$ then

begin

$\mathrm{j}:=\mathrm{j}+1$;

checkbox 12.color:=clred;

button2.click;

end;

if (fert=1) and (i=1) then

begin

$\mathrm{c}:=\mathrm{c}+1$;

end;

if (c>5) and (' $0{ }^{\prime}=s 3($ bit $\left.)\right)$ then

begin

$\mathrm{i}:=2 ; \quad$ checkbox11.checked:=false;

checkbox12.checked:=false;

checkbox11.color:=clblack;

checkbox12.color:=clblack;

$\mathrm{c}:=0 ; \mathrm{j}:=0 ;$ agua: $=0 ;$ fert: $=0$; bits:='0000';

carrinho1(bits);

\{ÚLTIMA IRRIGAÇÃO\}

horaatual:=now; $\quad$ edit6.text:=";

reset(horadatat); rewrite(horadatat);

write(horadatat,datetimetostr(horaatual)+'

'+'NA='+inttostr(pa)+' '+'NF='+inttostr(pf)); 


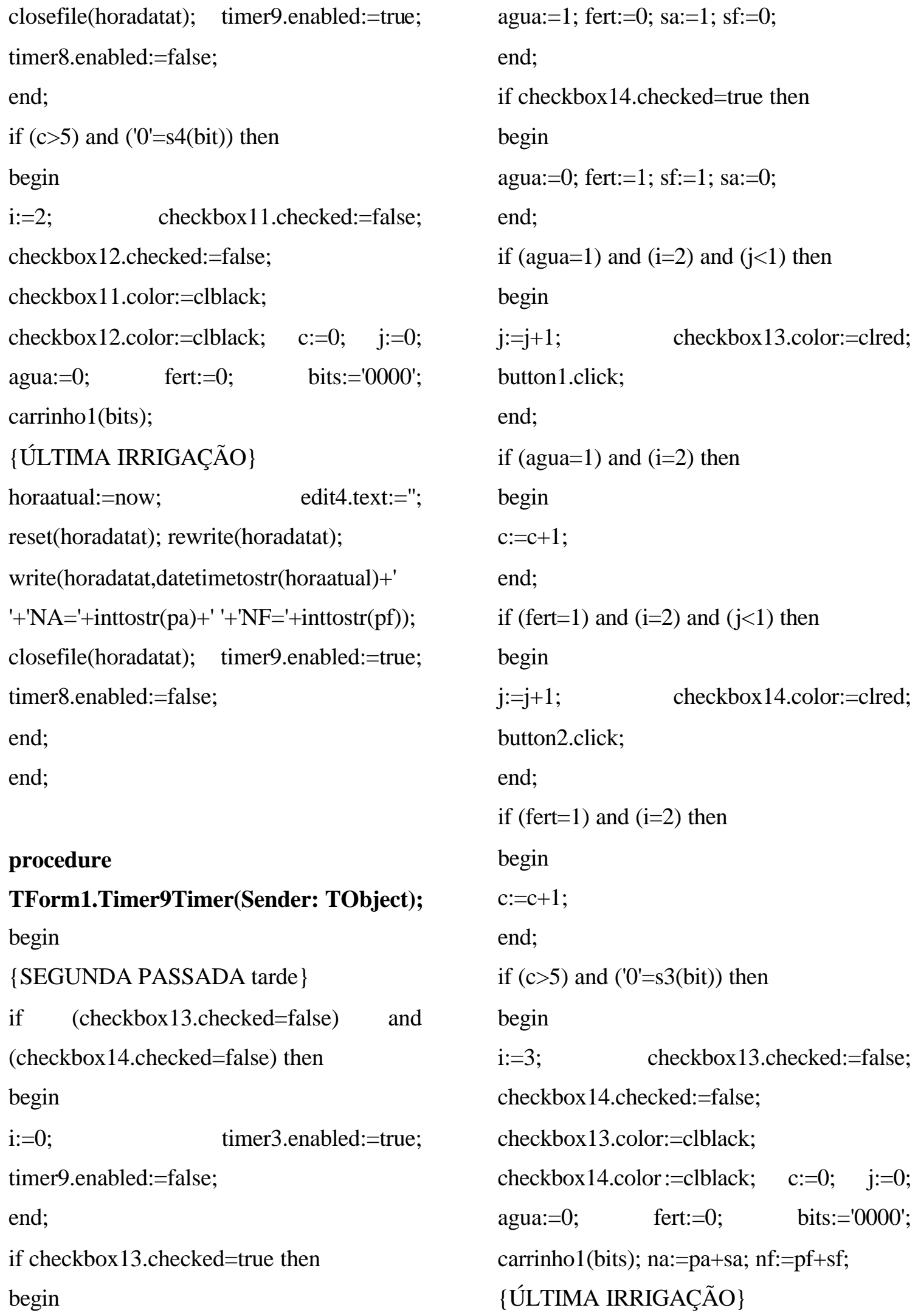




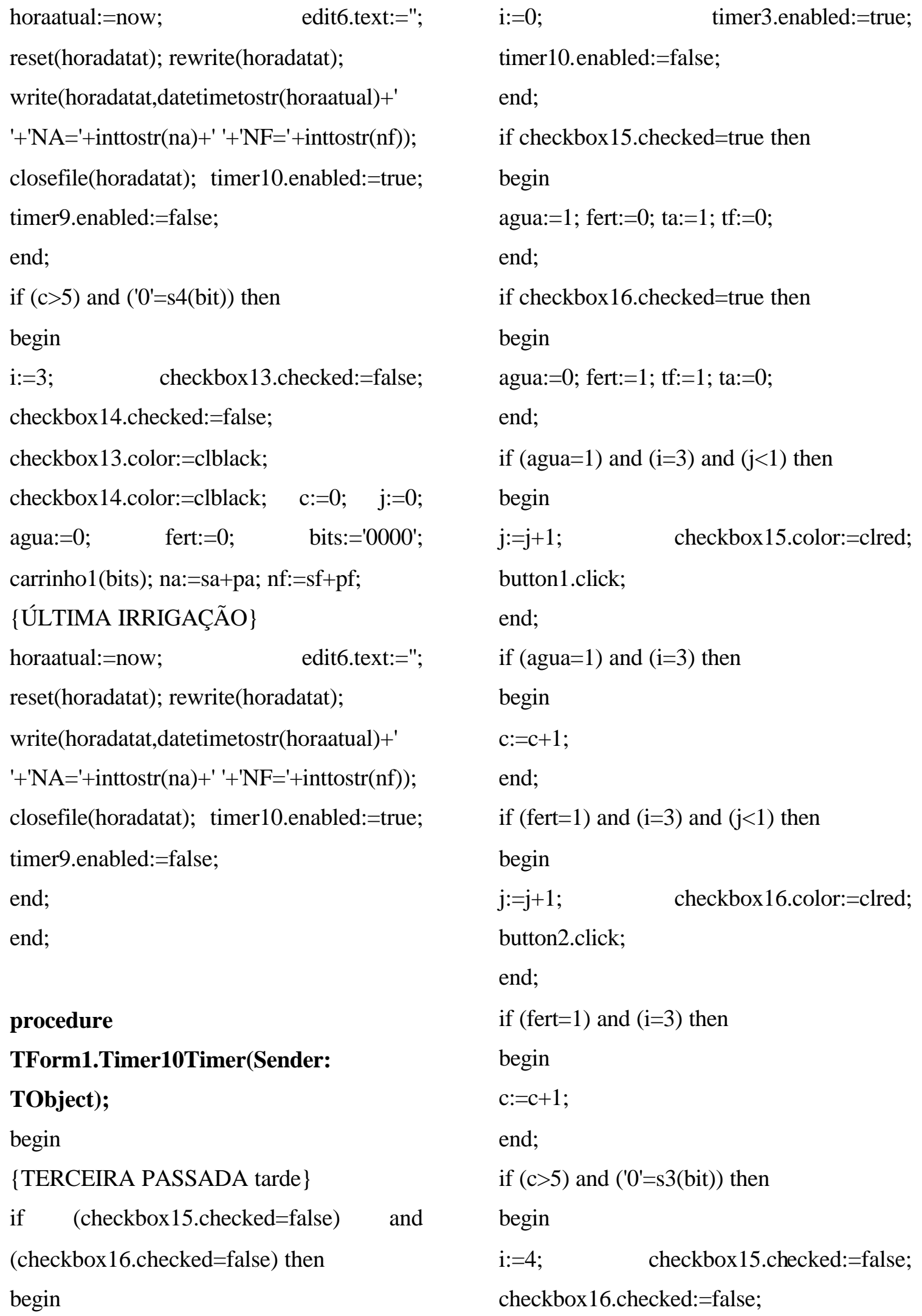




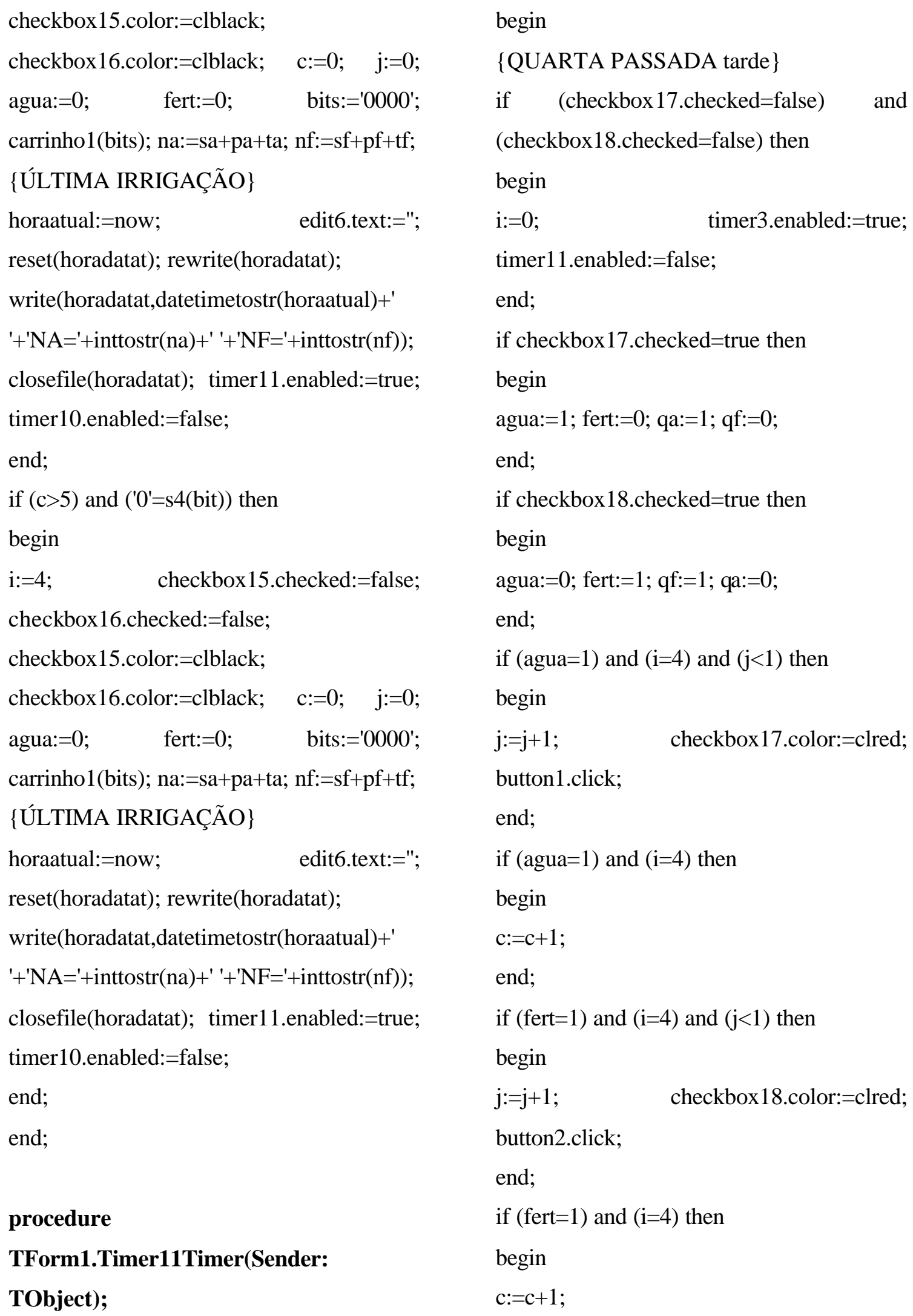


end;

if (c>5) and (' $\left.0{ }^{\prime}=\mathrm{s} 3(\mathrm{bit})\right)$ then

begin

$\mathrm{i}:=5 ; \quad$ checkbox17.checked:=false;

checkbox18.checked:=false;

checkbox17.color:=clblack;

checkbox18.color:=clblack; $\quad \mathrm{c}:=0 ; \quad \mathrm{j}:=0$;

agua: $=0 ; \quad$ fert: $=0 ; \quad$ bits:='0000';

carrinho1(bits); $\quad$ na: $=$ sa+pa+ta+qa;

$\mathrm{nf}:=\mathrm{sf}+\mathrm{pf}+\mathrm{tf}+\mathrm{qf}$;

\{ÚLTIMA IRRIGAÇÃO\}

horaatual:=now; $\quad$ edit6.text:=";

reset(horadatat); rewrite(horadatat);

write(horadatat,datetimetostr(horaatual)+'

'+'NA='+inttostr(na)+' '+'NF='+inttostr(nf));

closefile(horadatat); timer12.enabled:=true;

timer11.enabled:=false;

end;

if (c>5) and (' $\left.0^{\prime}=\mathrm{s} 4(\mathrm{bit})\right)$ then

begin

$\mathrm{i}:=5 ; \quad$ checkbox17.checked:=false;

checkbox18.checked:=false;

checkbox17.color:=clblack;

checkbox18.color:=clblack; $\quad \mathrm{c}:=0 ; \quad \mathrm{j}:=0$;

agua: $=0 ; \quad$ fert: $=0 ; \quad$ bits:='0000';

carrinho1(bits); $\quad$ na: $=$ sa + pa+ta+qa;

nf:=sf+pf+tf+qf;

\{ÚLTIMA IRRIGAÇÃO\}

horaatual:=now;

edit6.text:=";

reset(horadatat); rewrite(horadatat);

write(horadatat,datetimetostr(horaatual)+'

'+'NA='+inttostr(na)+' '+'NF='+inttostr(nf)); closefile(horadatat); timer12.enabled:=true; timer11.enabled:=false;

end;

end;

procedure

TForm1.Timer12Timer(Sender:

TObject);

begin

\{QUINTA PASSADA tarde\}

if (checkbox19.checked=false) and

(checkbox 20.checked=false) then

begin

$\mathrm{i}:=0 ; \quad$ timer3.enabled:=true;

timer12.enabled:=false;

end;

if checkbox 19. checked=true then

begin

agua:=1; fert:=0; quia:=1; quif:=0;

end;

if checkbox 20. checked=true then

begin

agua:=0; fert:=1; quif:=1; quia:=0;

end;

if (agua=1) and $(\mathrm{i}=5)$ and $(\mathrm{j}<1)$ then

begin

$\mathrm{j}:=\mathrm{j}+1 ; \quad \quad$ checkbox19.color:=clred;

button1.click;

end;

if (agua $=1)$ and $(i=5)$ then

begin

$\mathrm{c}:=\mathrm{c}+1$;

end; 
if (fert=1) and $(\mathrm{i}=5)$ and $(\mathrm{j}<1)$ then

begin

$\mathrm{j}:=\mathrm{j}+1 ; \quad$ checkbox20.color:=clred;

button2.click;

end;

if (fert=1) and (i=5) then

begin

$\mathrm{c}:=\mathrm{c}+1$;

end;

if (c>5) and (' $0{ }^{\prime}=\mathrm{s} 3($ bit $\left.)\right)$ then

begin

$\mathrm{i}:=0 ; \quad$ checkbox19.checked:=false;

checkbox20.checked:=false;

checkbox19.color:=clblack;

checkbox20.color:=clblack; $\quad \mathrm{c}:=0 ; \quad \mathrm{j}:=0$;

agua: $=0 ; \quad$ fert: $=0 ; \quad$ bits:='0000';

carrinho1(bits); na:=sa+pa+ta+qa+quia;

$\mathrm{nf}:=\mathrm{sf}+\mathrm{pf}+\mathrm{tf}+\mathrm{qf}+$ quif;

\{ÚLTIMA IRRIGAÇÃO\}

horaatual:=now; edit6.text:=";

reset(horadatat); rewrite(horadatat);

write(horadatat,datetimetostr(horaatual)+'

'+'NA='+inttostr(na)+' '+'NF='+inttostr(nf));

closefile(horadatat); timer3.enabled:=true;

timer12.enabled:=false;

end;

if (c>5) and (' $0{ }^{\prime}=\mathrm{s} 4($ bit $\left.)\right)$ then

begin

$\mathrm{i}:=0 ; \quad$ checkbox19.checked:=false;

checkbox20.checked:=false;

checkbox19.color:=clblack;

checkbox20.color:=clblack; $\quad \mathrm{c}:=0 ; \quad \mathrm{j}:=0$;

agua: $=0 ; \quad$ fert: $=0 ; \quad$ bits:='0000';

carrinho1(bits); $\quad$ na:=sa+pa+ta+qa+quia;

$\mathrm{nf}:=\mathrm{sf}+\mathrm{pf}+\mathrm{tf}+\mathrm{qf}+$ quif;

\{ÚLTIMA IRRIGAÇÃO\}

horaatual:=now; $\quad$ edit6.text:=";

reset(horadatat); rewrite(horadatat);

write(horadatat,datetimetostr(horaatual)+'

'+'NA='+inttostr(quia)+'

'+'NF='+inttostr(quif));

closefile(horadatat); timer3.enabled:=true;

timer12.enabled:=false;

end;

end;

procedure

TForm1.CheckBox21Click(Sender:

TObject);

begin

edit5.text:=";

end;

procedure

TForm1.Che ckBox22Click(Sender:

TObject);

begin

edit2.text:=";

end;

procedure

TForm1.ScrollBar7Change(Sender:

TObject);

begin 


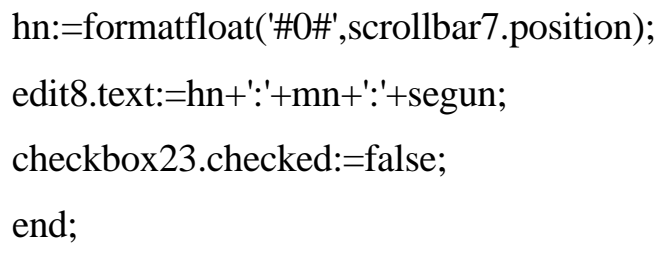

begin

\{PIMEIRA PASSADA noite\}

if (checkbox24.checked=false) and (checkbox25.checked=false) then

begin

$\mathrm{i}:=0 ; \quad$ timer3.enabled:=true;

timer13.enabled:=false;

end;

if checkbox 24.checked=true then begin

agua: $=1$; fert: $=0 ;$ pa: $=1 ;$ pf: $=0$;

end;

if checkbox 25 .checked=true then

begin

agua: $=0$; fert: $=1 ;$ pf:=1; pa: $=0$;

end;

if $($ agua $=1)$ and $(i=1)$ and $(j<1)$ then

begin

$\mathrm{j}:=\mathrm{j}+1 ; \quad$ checkbox24.color:=clred;

button1.click;

end;

if (agua=1) and $(\mathrm{i}=1)$ then

begin

$\mathrm{c}:=\mathrm{c}+1$;

end;

if (fert=1) and $(\mathrm{i}=1)$ and $(\mathrm{j}<1)$ then

begin

$\mathrm{j}:=\mathrm{j}+1 ; \quad \quad$ checkbox25.color:=clred;

button2.click;

end;

if (fert=1) and $(\mathrm{i}=1)$ then

begin

$\mathrm{c}:=\mathrm{c}+1$; 
end;

if $(c>5)$ and $\left(' 0^{\prime}=s 3(b i t)\right)$ then

begin

$\mathrm{i}:=2 ; \quad$ checkbox24.checked:=false;

checkbox25.checked:=false;

checkbox24.color:=clblack;

checkbox 25.color:=clblack; $\quad \mathrm{c}:=0 ; \quad \mathrm{j}:=0$;

agua: $=0 ; \quad$ fert: $=0 ; \quad$ bits:='0000';

carrinho1(bits);

\section{\{ÚLTIMA IRRIGAÇÃO\}}

horaatual:=now;

edit7.text:=";

reset(horadatan); rewrite(horadatan);

write(horadatan, datetimetostr(horaatual)+'

'+'NA='+inttostr(pa)+' '+'NF='+inttostr(pf));

closefile(horadatan); timer14.enabled:=true;

timer13.enabled:=false;

end;

if (c>5) and (' $\left.0{ }^{\prime}=\mathrm{s} 4(\mathrm{bit})\right)$ then

begin

$\mathrm{i}:=2 ; \quad$ checkbox24.checked:=false;

checkbox25.checked:=false;

checkbox24.color:=clblack;

checkbox25.color:=clblack; $\quad \mathrm{c}:=0 ; \quad \mathrm{j}:=0$;

agua: $=0 ; \quad$ fert: $=0 ; \quad$ bits:='0000';

carrinhol(bits);

\{ÚLTIMA IRRIGAÇÃO\}

horaatual:=now;

edit7.text:=";

reset(horadatan); rewrite(horadatan);

write(horadatan, datetimetostr(horaatual)+'

'+'NA='+inttostr(pa)+' '+'NF='+inttostr(pf));

closefile(horadatan); timer14.enabled:=true;

timer13.enabled:=false;

end; end;

\section{procedure}

\section{TForm1.Timer14Timer(Sender:}

\section{TObject);}

begin

\{SEGUNDA PASSADA noite\}

if (checkbox26.checked=false) and (checkbox27.checked=false) then begin

$\mathrm{i}:=0 ; \quad$ timer3.enabled:=true;

end;

if checkbox26.checked=true then

begin

agua: $=1$; fert: $=0 ;$ sa: $=1 ;$ sf: $=0$;

end;

if checkbox 27 .checked=true then

begin

agua: $=0 ;$ fert:=1; sf:=1; sa: $=0$;

end;

if (agua=1) and $(\mathrm{i}=2)$ and $(\mathrm{j}<1)$ then

begin

$\mathrm{j}:=\mathrm{j}+1 ; \quad \quad$ checkbox26.color:=clred;

button1.click;

end;

if (agua=1) and $(\mathrm{i}=2)$ then

begin

$\mathrm{c}:=\mathrm{c}+1$;

end;

if (fert=1) and $(\mathrm{i}=2)$ and $(\mathrm{j}<1)$ then

begin 


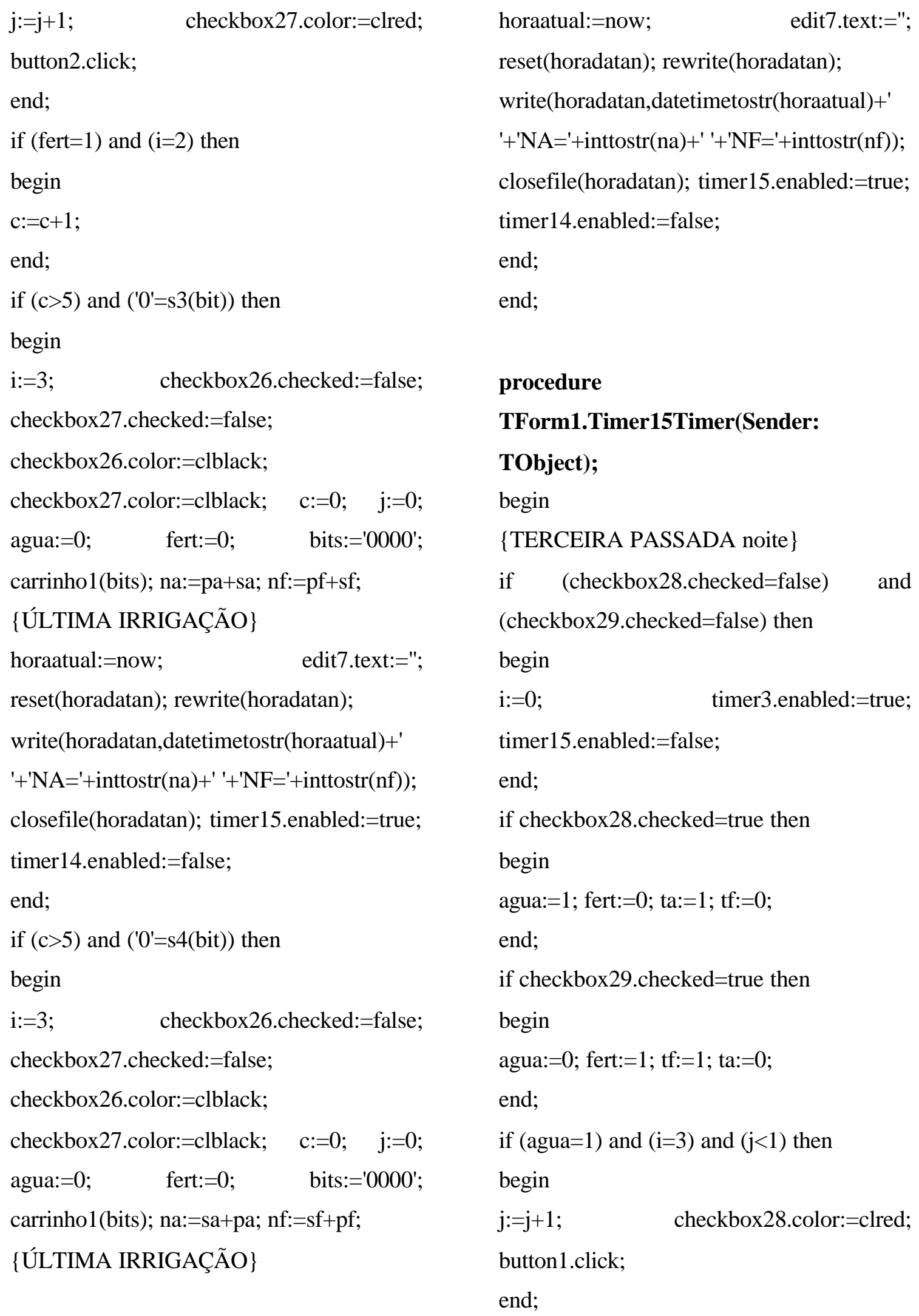




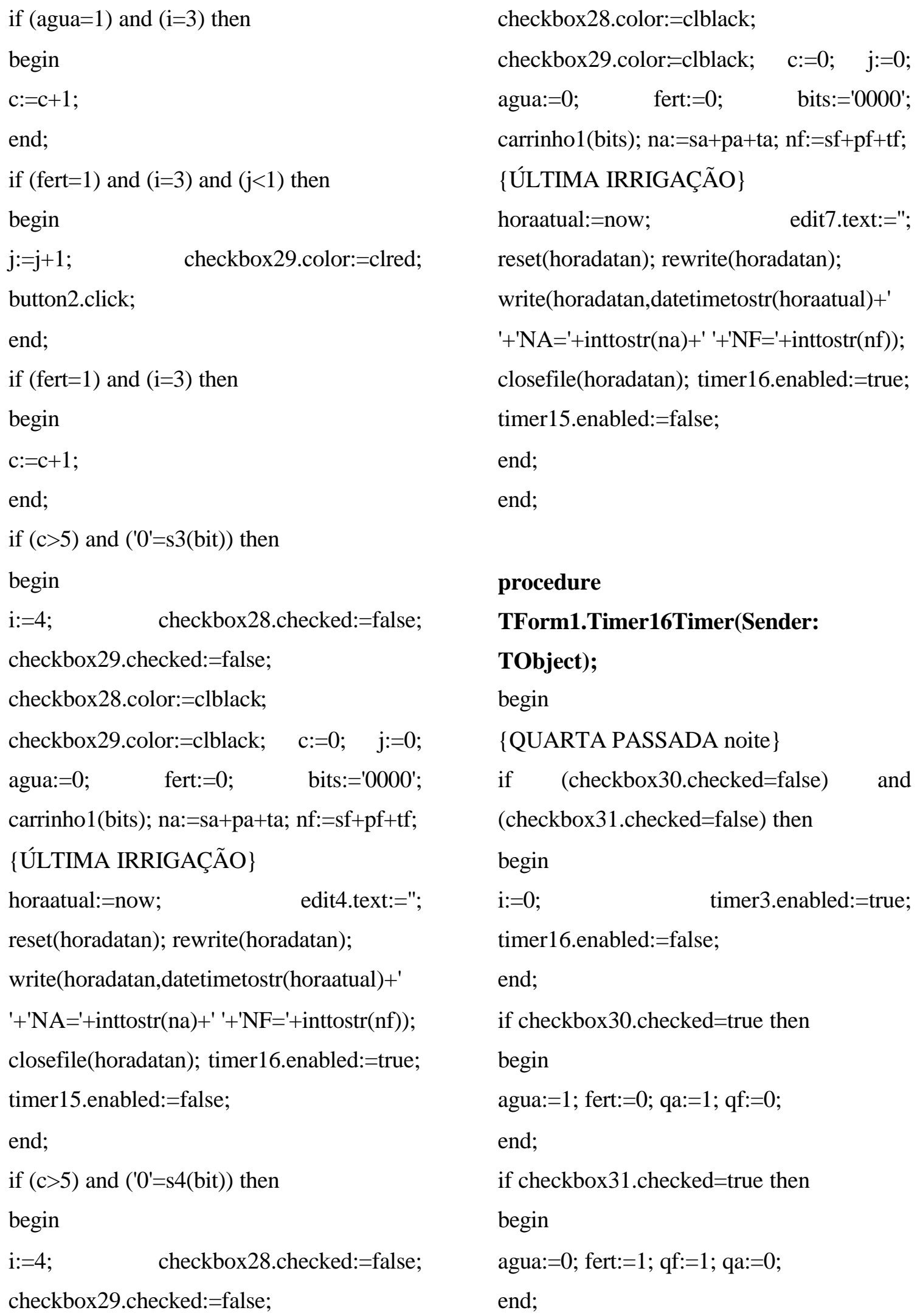


if (agua=1) and $(\mathrm{i}=4)$ and $(\mathrm{j}<1)$ then

begin

$\mathrm{j}:=\mathrm{j}+1 ; \quad \quad$ checkbox30.color:=clred;

button1.click;

end;

if (agua=1) and (i=4) then

begin

$\mathrm{c}:=\mathrm{c}+1$;

end;

if (fert=1) and $(\mathrm{i}=4)$ and $(\mathrm{j}<1)$ then

begin

$\mathrm{j}:=\mathrm{j}+1 ; \quad \quad$ checkbox31.color:=clred;

button2.click;

end;

if (fert=1) and ( $\mathrm{i}=4)$ then

begin

$\mathrm{c}:=\mathrm{c}+1$;

end;

if (c>5) and (' $\left.0{ }^{\prime}=\mathrm{s} 3(\mathrm{bit})\right)$ then

begin

$\mathrm{i}:=5 ; \quad$ checkbox30.checked:=false;

checkbox31.checked:=false;

checkbox30.color:=clblack;

checkbox31.color: $=$ clblack; $\quad \mathrm{c}:=0 ; \quad \mathrm{j}:=0$;

agua: $=0 ; \quad$ fert: $=0 ; \quad$ bits:='0000';

carrinho1(bits); na: $=$ sa+pa+ta+qa;

$\mathrm{nf}:=\mathrm{sf}+\mathrm{pf}+\mathrm{tf}+\mathrm{qf}$;

\{ÚLTIMA IRRIGAÇÃO\}

horaatual:=now;

edit7.text:=";

reset(horadatan); rewrite(horadatan);

write(horadatan, datetimetostr(horaatual)+'

'+'NA='+inttostr(na)+' '+'NF='+inttostr(nf)); closefile(horadatan); timer17.enabled:=true; timer16.enabled:=false;

end;

if (c>5) and (' 0 '=s4(bit)) then

begin

$\mathrm{i}:=5 ; \quad$ checkbox30.checked:=false;

checkbox31.checked:=false;

checkbox30.color:=clblack;

checkbox31.color: $=$ clblack; $\quad \mathrm{c}:=0 ; \quad \mathrm{j}:=0$;

agua: $=0 ; \quad$ fert: $=0 ; \quad$ bits:='0000';

carrinho1(bits); na:=sa+pa+ta+qa;

$\mathrm{nf}:=\mathrm{sf}+\mathrm{pf}+\mathrm{tf}+\mathrm{qf}$;

\{ÚLTIMA IRRIGAÇÃO\}

horaatual:=now; $\quad$ edit7.text:=";

reset(horadatan); rewrite(horadatan);

write(horadatan, datetimetostr(horaatual)+'

'+'NA='+inttostr(na)+' '+'NF='+inttostr(nf));

closefile(horadatan); timer17.enabled:=true;

timer16.enabled:=false;

end;

end;

procedure

TForm1.Timer17Timer(Sender:

TObject);

begin

\{QUINTA PASSADA noite\}

if (checkbox32.checked=false) and

(checkbox33.checked=false) then

begin

$\mathrm{i}:=0 ; \quad$ timer3.enabled:=true;

timer17.enabled:=false;

end; 
if checkbox32. checked=true then

begin

agua: $=1$; fert: $=0$; quia: $=1 ;$ quif: $=0$;

end;

if checkbox33.checked=true then

begin

agua:=0; fert:=1; quif:=1; quia:=0;

end;

if (agua=1) and $(\mathrm{i}=5)$ and $(\mathrm{j}<1)$ then

begin

$\mathrm{j}:=\mathrm{j}+1 ; \quad$ checkbox32.color:=clred;

button1.click;

end;

if (agua=1) and $(\mathrm{i}=5)$ then

begin

$\mathrm{c}:=\mathrm{c}+1$;

end;

if (fert=1) and $(i=5)$ and $(j<1)$ then

begin

$\mathrm{j}:=\mathrm{j}+1 ; \quad$ checkbox33.color:=clred;

button2.click;

end;

if (fert=1) and ( $\mathrm{i}=5)$ then

begin

$\mathrm{c}:=\mathrm{c}+1$;

end;

if (c>5) and (' $0{ }^{\prime}=\mathrm{s} 3($ bit $\left.)\right)$ then

begin

$\mathrm{i}:=0 ; \quad \quad$ checkbox32.checked:=false;

checkbox33.checked:=false;

checkbox32.color:=clblack;

checkbox33.color:=clblack; $\quad \mathrm{c}:=0 ; \quad \mathrm{j}:=0$;

agua: $=0 ; \quad$ fert: $=0 ; \quad$ bits:='0000'; carrinho1(bits); na:=sa+pa+ta+qa+quia;

$\mathrm{nf}:=\mathrm{sf}+\mathrm{pf}+\mathrm{tf}+\mathrm{qf}+$ quif;

\{ÚLTIMA IRRIGAÇÃO\}

horaatual:=now;

edit7.text:=";

reset(horadatan); rewrite(horadatan);

write(horadatan, datetimetostr(horaatual)+'

'+'NA='+inttostr(na)+' '+'NF='+inttostr(nf));

closefile(horadatan); timer3.enabled:=true;

timer17.enabled:=false;

end;

if (c>5) and (' 0 '=s4(bit)) then

begin

$\mathrm{i}:=0 ; \quad$ checkbox32.checked:=false;

checkbox33.checked:=false;

checkbox32.color:=clblack;

checkbox33.color: $=$ clblack; $\quad \mathrm{c}:=0 ; \quad \mathrm{j}:=0$;

agua:=0; fert:=0; bits:='0000';

carrinho1(bits); na:=sa+pa+ta+qa+quia;

$\mathrm{nf}:=\mathrm{sf}+\mathrm{pf}+\mathrm{tf}+\mathrm{qf}+$ quif;

\{ÚLTIMA IRRIGAÇÃO\}

horaatual:=now; $\quad$ edit7.text:=";

reset(horadatan); rewrite(horadatan);

write(horadatan, datetimetostr(horaatual)+'

'+'NA='+inttostr(quia)+'

'+'NF='+inttostr(quif));

closefile(horadatan); timer3.enabled:=true;

timer17.enabled:=false;

end;

end;

procedure

TForm1.Button8Click(Sender: TObject);

begin 


$\begin{array}{ll}\text { bits:='0000'; } & \text { procedure } \\ \text { timer3.enabled:=false; } & \text { TForm1.Button11Click(Sender: } \\ \text { end; } & \text { TObject); } \\ & \text { begin } \\ \text { procedure } & \text { form1.Color:=clblack; } \\ \text { TForm1.Button9Click(Sender: TObject); } & \text { button3.visible:=true; button4.visible:=true; } \\ \text { begin } & \text { button8.visible:=true; button9.vis ible:=true; } \\ \text { timer3.enabled:=true; } & \text { button11.visible:=false; edit3.visible:=false; } \\ \text { end; } & \text { image1.Visible:=false; } \\ & \text { label34.Visible:=true; } \\ \text { procedure } & \text { label35.visible:=false; } \\ \text { TForm1.Button10Click(Sender: } & \text { label36.visible:=false; } \\ \text { TObject); } & \text { label37.visible:=false; } \\ \text { begin } & \text { button10.visible:=true; label7.visible:=true; } \\ \text { close; } & \text { edit1.visible:=true; } \\ \text { end; } & \text { end; } \\ & \text { end. }\end{array}$




\section{REFERÊNCIAS BIBLIOGRÁFICAS}

ASSOCIAÇÃO BRASILEIRA DE NORMAS TÉCNICAS. Requisitos mínimos para elaboração de projeto de sistema de irrigação localizada; PNBR 12:02-08-022. São Paulo, 1986. 18p.

ASSOCIAÇÃO BRASILEIRA DE NORMAS TÉCNICAS. Equipamentos de irrigação mecanizada - Pivô central e lateral móvel providos de emissores fixos ou rotativos - Determinação da uniformidade de distribuição de água; NBR 14244. São Paulo, 1998. 11p.

BENAMI, A.; HORE, F.R. A new irrigation-sprinkler distribution coefficient. Transactions of the ASAE, v.7, n.2, p.157-158, 1962.

BOTREL, T.A. Hidráulica de microaspersores e de linhas laterais para irrigação localizada. Piracicaba, 1984. 78p. Dissertação (Mestrado) - Escola Superior de Agricultura "Luiz de Queiroz", Universidade de São Paulo.

BRAGA, N.C. Curso básico de eletrônica. São Paulo: Editora Saber, 1999. v.1, 140p.

CARVALHO, D.F.; SILVA, W.A.; MÉDICE, L.O.; PEREIRA, M.G. Avaliação de um sistema automático de baixo custo para manejo da irrigação (compact disc). In: CONGRESSO BRASILEIRO DE ENGENHARIA AGRÍCOLA, 30., Foz do Iguaçu, 2001. Anais. Foz do Uguaçu: SBEA, 2001. 
CASTRUCCI, P.B.L Controle automático: teoria e projeto. São Paulo: EDUSP, 1969. 280p.

CHRISTIANSEN, J.E. Irrigation by sprinkling. Berkeley: University of California, Experiment Station., 1942. 124p. (Bulletin, 670).

COELHO, R.D. Regulagens de aspersores e seus efeitos sobre a uniformidade de aplicação de água e produtividade das culturas. Piracicaba, 1990. 141p. Dissertação (Mestrado) - Escola Superior de Agricultura "Luiz de Queiroz", Universidade de São Paulo.

DODI JUNIOR, C. Construção de um sistema coletor automático para ensaio de microaspersores. In: CONGRESSO BRASILEIRO DE ENGENHARIA AGRÍCOLA, 1999, Piracicaba, 1990. Anais. Piracicaba: SBEA, 1990. v.1, p.628.

FIALHO, F.B. Modernização no controle da produção de suínos - zootecnia de precisão. In: SIMPÓSIO BRASILEIRO DE AMBIÊNCIA E QUALIDADE NA PRODUÇÀO INDUSTRIAL DE SUÍNOS, Piracicaba, 1999. Resumos. Piracicaba: FEALQ, 1999. p. 61-80.

FREIRE, C.R.F. Análise do trabalho rural no Nordeste do Brasil. Piracicaba, 2000. 75p. Dissertação (Mestrado) - Escola Superior de Agricultura "Luiz de Queiroz", Universidade de São Paulo.

FRIZZONE, J.A. Irrigação por aspersão: uniformidade e eficiência. Piracicaba: ESALQ, Depto. de Engenharia Rural, 1992. 53p. (Série Didática, 3)

FUNDAÇÃO INSTITUTO BRASILEIRO DE GEOGRAFIA E ESTATÍSTICA. Contagem da população. Rio de janeiro: IBGE, 1996. 
GOMIDE, R.L.; BERNARDO, S.; VIEIRA, M.; SEDIYAMA, G.C. Análise da uniformidade de distribuição da água no sistema de irrigação por aspersão. Revista Ceres, v.27, n.153, p.457-470, 1980.

GORNAT, B.; SILVA, W.L.V. Sistemas de controle e automatização da irrigação. ITEM. Irrigação e Tecnologia Moderna, n.41, p.20-24, 1990.

HART, W.E. Overhead irrigation pattern parameters. Agricultural Engineering, v.42, n.7, p. 83-89, 1961.

KARMELI, D. Estimating sprinkler distribution patterns using linear regression. Transactions of the ASAE, v.21, n.2, p.682-685. 1978.

KELLER, J. Sprinkler irrigation. Logan: Utah State University, 1984. 621p.

KELLER, J.; BLIESNER, R.D. Sprinkle and trickle irrigation New York: Von Nostrand Reinold, 1990, 280p.

KELLER, J.; KARMELI, D. Trickle irrigation design parameters. Transactions of the ASAE, v.17, n.2, p.678-684, July/Aug. 1974.

KRUSE, E.G. Describing irrigation efficiency and uniformity. Journal Irrigation Drainage Division ASCE, v.104, n.1, p.35-41. 1978.

MORAES, O. Efeito do uso de polímero hidroretentorno solo sobre o intervalo de irrigação na cultura da alface. Piracicaba, 2001. 73p. Tese (Doutorado) - Escola Superior de Agricultura “Luiz de Queiroz”, Universidade de São Paulo. 
MUNDIM, P.M. Uniformidade de distribuição de água por aspersão convencional na presença da cultura do milho. Piracicaba, 1996. 82p. Dissertação (Mestrado) - Escola Superior de Agricultura “Luiz de Queiroz", Universidade de São Paulo.

REZENDE, R. Desempenho de um sistema de irrigação pivô central quanto à uniformidade e eficiência de aplicação de água abaixo e acima da superfície do solo. Piracicaba, 1992. 86p. Dissertação (Mestrado)- Escola Superior de Agricultura "Luiz de Queiroz”, Universidade de São Paulo.

ROCHA, F.E.C.; ANDRADE, L.M.; AZEVEDO, J.A.; SILVA, E.M.; FOLLE, S.M.; FRANZ, A.B.; GOMES, A.C. Desenvolvimento de um equipamento de irrigação com deslocamento linear para parcelas experimentais. Pesquisa Agropecuária Brasileira, v.33, n.4, p.471-479, 1998.

RODRIGUES, L.N.; MELLO, J.L.P.; MANTOVANI, E.C.; RAMOS, M.M. Coeficientes de uniformidade: sensibilidade a mudanças nos fatores operacionais. IRRIGA, v.2, n.2, p.90-99, 1997.

SALES, J.C. Avaliação de Coeficientes de Uniformidade de distribuição e Perdas de Água por Aspersão Convencional. Fortaleza, 1997. 68p. Dissertação (Mestrado)Universidade Federal do Ceará.

SILVA, D.D.; RAMOS, M.M.; MARTINEZ, M.A.; DENÍCULI, W. Uniformidade de distribuição de água em sistemas de aspersão, com utilização de aspersor fixo com placa defletora auxiliar. Engenharia Agrícola, v.5, n.4, p.281-292, 1997.

SILVA, I.J. Desenvolvimento de modelos matemáticos para análise da influência das condições ambientais na produção de ovos. Campinas, 1998. 140p. Tese (Doutorado)- Faculdade de Engenharia Agrícola, Universidade Estadual de Campinas. 
SILVA, K.O. Desenvolvimento de sistema automatizado de baixo custo para aquisição de dados de umidade e temperatura do ar. Piracicaba, 2000. 70p. Dissertação (Mestrado)- Escola Superior de Agricultura "Luiz de Queiroz", Universidade de São Paulo.

SOLOMON, K.H. Manufacturing variation of trickle emitters. Transactions of The ASAE, v.22, n.5, p. 1034-1038, Sept./Oct. 1979.

SOLOMON, K.H. Yield related interpretations of uniformity measures. Irrigation Science, v.5, n.3, p.161-172, 1984.

VIEIRA, A.T. Caracterização hidráulica de um tubo gotejador. Piracicaba, 1996. 56p. Dissertação (Mestrado) - Escola Superior de Agricultura "Luiz de Queiroz", Universidade de São Paulo.

VILELA, E.D.D. Acesso a porta paralela do PC. Saber Eletrônica, n.319, p. 42-43, 1999.

WILCOX, J.C.; SWAILES, G.E. Uniformity of water distribuction by some undertree orchard sprinkler. Scientific Agriculture, v.27, n.11, p.565-583, 1947. 